\title{
International Financial Integration and The Real Economy
}

January 2, 2007

\author{
Martin D. D. Evans \\ Georgetown University and NBER \\ Department of Economics \\ Washington DC 20057 \\ Tel: (202) 338-2991 \\ evansm1@georgetown.edu
}

\author{
Viktoria Hnatkovska \\ UBC \\ Department of Economics \\ Vancouver BC V6K 3W9 \\ Tel: (604) 822-5941 \\ hnatkovs@interchange.ubc.ca
}

(Forthcoming, IMF Staff Papers)

\begin{abstract}
What are the consequences of financial integration for the real economy? This paper develops a set of theoretical benchmarks for the link between integration and macroeconomic volatility and welfare. The analysis is conducted in a standard two-sector international real business cycle model in which we introduce dynamic portfolio choice over equities and an international bond. The model predicts an increase in the volatility of output in response to integration, while the relation between integration and consumption volatility is hump-shaped. We also find that financial integration is associated with significant improvement in risk-sharing across countries, although in aggregate the welfare benefits are very small. At the same time, the level of financial integration significantly affects how the welfare benefits of productivity shocks are distributed internationally.
\end{abstract}

JEL Classification: D52; F36; G11.

Keywords: Globalization; Incomplete Markets; Volatility; Welfare. 


\section{Introduction}

By many measures, the world's financial markets have become increasingly integrated over the past twenty years; international capital flows have risen dramatically, there is greater foreign ownership of financial assets, and there are fewer impediments to international asset trading. The consequences of greater international financial integration for the real economy are less clear. Does increased financial integration lead to greater macroeconomic volatility because national economies become more susceptible to foreign shocks or to less volatility because their is greater scope for risk-sharing? More importantly, how does the degree of financial integration affect welfare? Does everyone gain from greater financial integration, or are there "winners" and "losers"? In this paper, we address these questions from the perspective of a standard two-sector international real business cycle model. Our aim is to establish the theoretical links between integration and macroeconomic volatility and welfare implied by a canonical international macroeconomic model.

We model financial integration as a gradual removal of the restrictions on the international asset trades in a two-country, two-sector real business cycle model. We start by looking at the properties of this model when access to international financial markets is prohibited (financial autarky). This analysis serves as a benchmark for understanding the effects of integration. Next, we consider a low integration equilibrium in which households can trade an international non-contingent bond. Finally, we study a high integration equilibrium in which households trade international bonds and equities issued by a subset of foreign firms. This comparative approach to modeling integration is not new to the literature; it as been employed by Baxter and Crucini (1995), Heathcote and Perri (2002), and others.

Our analysis has two notable features. First, in all three equilibria we consider, international risk-sharing among households is less than perfect. As we move from financial autarky to low integration and then to high integration, the degree of risk-sharing increases, but households never have access to a rich enough array of financial assets to make markets complete. In view of the ample empirical evidence documenting incomplete risk-sharing, we view this as an important feature of the model. The second feature concerns the presence of many financial assets. We study how the portfolio choices of households adjust to the expanding array of international assets that become available under greater financial integration, and how these portfolio choices affect the real economy and welfare. In this respect, this paper adds to a growing literature studying general equilibrium models with portfolio choice. ${ }^{1}$

Our analysis generates four principal findings: First, we find that the relation between integration and the volatility of aggregate consumption is hump-shaped. Consumption volatility is higher at low levels of financial integration than under either financial autarky, or high integration. The intuition for this result is straightforward. In our model, aggregate consumption comprises a basket of traded and nontraded goods, so there are two effects to consider. First, the volatility of traded consumption declines as households gain access for better means of risk-sharing. Second, enhanced risk-sharing enables households to balance their consumption of traded and nontraded goods. Initially, when international bonds become available in the low integration equilibrium, the second effect dominates and the aggregate consumption volatility increases.

\footnotetext{
${ }^{1}$ See, see Evans and Hnatkovska (2005), Devereux and Sutherland (2006), Tille and van Wincoop (2006), and Ghironi, Lee and Rebucci (2006)
} 
Then, when international equity becomes available in the high integration equilibrium, the benefits of greater portfolio diversification dominate, leading to lower volatility of aggregate consumption.

Our second main finding concerns the volatility of output. The volatility of output growth increases with the degree of financial integration, but the largest rise appears when moving from financial autarky to low integration. We find that the volatility of real investment contributes most to this increase in volatility. When households have greater access to international capital markets, firms have a larger incentive to take advantage of variations in the marginal product of capital by varying their investment expenditures because households are better able to smooth consumption in the face of the associated variations in dividends. Consequently, real investment becomes more volatile and procyclical as financial integration increases.

Third, greater financial integration allows for a higher degree of international risk-sharing. We find that the largest risk-sharing gains occur between financial autarky and low integration where households have access to the international bond market. When households gain access to foreign equities there is a further risk-sharing gain, but it is much smaller. The reason is that the potential risk-sharing gains from equity diversification in the low integration equilibrium are offset by the structural change in the behavior of equity prices as the degree of financial integration increases. We calculate that the structural change lowers the degree of risk-sharing achieved under high integration by $38 \%$. Thus, there is a significant difference between the ex ante risk-sharing gains from equity diversification and the ex post gains once we account for the general equilibrium effects of higher integration on the behavior of equity prices.

Our fourth finding concerns welfare. Increased integration raises world welfare, but the welfare gain is extremely small because there is no change in the world's long-run growth rate. Nevertheless, integration does affect the distribution of welfare across countries. In particular, we show that the degree of financial integration has a significant impact on how the welfare consequences of different shocks are distributed through time and across countries. Consequently, it is possible that the households of a particular country could be worse off following a move from financial autarky, to low and then high integration.

Our study is related to two main strands of the literature: one strand studying the effects of integration on business cycle volatility; the other strand examining the risk-sharing implications of integration and its consequences for cross-country correlations. We discuss each of them in turn.

The empirical literature studying the effects of financial integration on macroeconomic volatility has generally been inconclusive. Razin and Rose (1994) find no significant relation between financial and trade openness and volatilities of consumption, output, and investment between 1950 and 1988 in their sample of 138 countries. Kose et. al. (2003) study a sample of 76 countries over the period of 1960 - 1999. They find that output volatility is lower for more financially integrated countries. The link between financial openness and consumption volatility, however, is found to be nonlinear. In particular, the association between the two appears to be positive, but only up to a certain threshold, after which the relation reverses. Theoretical studies generally predict that the volatility of consumption decreases with integration, but the results for output volatility are mixed. Baxter and Crucini (1995) and Heathcote and Perri (2002) find that the volatility of output increases with integration, but results are sensitive to the specification for productivity. When nominal rigidities are introduced, Sutherland (1998) finds that there is a general tendency for volatilities to decrease in response to higher financial market integration, but Senay (1998) reports mixed results for how 
financial and goods market integration affect volatilities. Buch and Pierdzioch (2003) introduce frictions, such as the financial accelerator and transaction costs in asset trades, but find that the link between integration and volatility is weak and is largely unaffected by the presence of financial imperfections. Leblebicioglu (2005) shows that some combinations of credit market frictions may lead to higher consumption volatility in response to integration. By contrast, our model generates the hump-shaped relation between the degree of integration and consumption volatility consistent with Kose et.al. (2003) without the presence of market frictions.

The literature has also evaluated the gains from international risk-sharing and its effects on cross-country correlations. Cole and Obstfeld (1991), Tesar (1995), and Gourinchas and Jeanne (2006), all find that the welfare gains resulting from moving between an economy with restricted asset trades to an economy with perfect capital mobility are small. Van Wincoop (1994, 1999), and Kim, Kim, and Levin (2003) report

larger gains and show how the estimates of the risk-sharing benefits in the endowment economy vary with the implicit risk-free rate, degree of relative risk aversion, risk-adjusted growth rate, and endowment uncertainty. Our results on the gains in aggregate welfare from integration are consistent with this literature, given the absence of long-run growth in our model, and our specification for preferences and productivity shocks.

The rest of the paper is organized as follows. Section 1 sets up the model we use to study the effects of integration. Section 2 characterizes the equilibrium, while Section 3 contains a detailed description of the solution technique. We present our results on macroeconomic volatility and welfare in Sections 4 and 5. Section 6 concludes.

\section{The Model}

We consider a world economy consisting of two identical countries, called HOME (н) and FOREIGN (F). Each country is populated by a continuum of identical households who supply their labor inelastically to domestic firms in the traded and nontraded goods sectors. Firms in both sectors are perfectly competitive, and issue equity that is traded on the domestic stock market. Our model is designed to study how the degree of financial integration affects risk sharing, the volatility of macroeconomic variables such as consumption and output, and their cross country comovements. For this purpose, we focus on three equilibria. First, we consider the benchmark case of financial autarky (FA). In this environment, households allocate their portfolios between equity issued by domestic firms producing traded and nontraded goods. Second, we consider a world with low integration (LI) where households allocate their portfolios between domestic equity and an international bond. Finally, we examine the case of high integration (HI). Here households can hold shares issued by foreign traded-good firms as well as domestic equities and the international bond. A key feature of the three equilibria we study \{i.e., FA, LI, HI $\}$ is that the array of assets available to households is insufficient to provide complete risk-sharing.

Below we first describe the production of traded and nontraded goods. Next we present the consumption, saving and portfolio choice problems facing households. Finally, we characterize the market clearing conditions that apply under different degrees of financial integration. 


\subsection{Production}

A continuum of identical firms comprise the traded goods sector in each country. Each firm owns its own capital and issues equity on the domestic stock market. The output in period $t$ of a representative firm in the H country's traded-goods sector is

$$
Y_{t}^{\mathrm{T}}=Z_{t}^{\mathrm{T}} K_{t}^{\theta}
$$

with $\theta>0$, where $K_{t}$ denotes the stock of physical capital at the start of the period, and $Z_{t}^{\mathrm{T}}$ is the exogenous state of productivity. The output of traded goods in the F country, $\hat{Y}_{t}^{\mathrm{T}}$, is given by an identical production function using foreign capital $\hat{K}_{t}$, and productivity $\hat{Z}_{t}^{\mathrm{T}}$. Hereafter we use "^" to denote foreign variables. The traded goods produced by $\mathrm{H}$ and $\mathrm{F}$ firms are identical and can be costlessly transported between countries. Under these conditions, the law of one price must prevail for traded goods to eliminate arbitrage opportunities.

At the beginning of each period, traded-goods' firms observe the current state of productivity, and then decide how to allocate output between consumption and investment goods. Output allocated to consumption is supplied competitively to domestic and foreign households and the proceeds are used to finance dividend payments to the owners of the firms' equity. Output allocated to investment adds to the stock of physical capital available for production next period. We assume that firms allocate output to maximize the value of the firm to its domestic shareholders.

Let $P_{t}^{\mathrm{T}}$ denote the ex-dividend price of a share in a representative $\mathrm{H}$ firm producing traded goods in period $t$, and $D_{t}^{\mathrm{T}}$ be the dividend per share paid at the start of period $t . P_{t}^{\mathrm{T}}$ and $D_{t}^{\mathrm{T}}$ are measured in terms of traded goods. We normalize the number of shares issued to unity so the value of a representative firm at the start of period $t$ is $P_{t}^{\mathrm{T}}+D_{t}^{\mathrm{T}}$. In period $t, \mathrm{H}$ traded-goods firms choose investment, $I_{t}$, as the solution to

subject to

$$
\begin{gathered}
\max _{I_{t}}\left(D_{t}^{\mathrm{T}}+P_{t}^{\mathrm{T}}\right), \\
K_{t+1}=(1-\delta) K_{t}+I_{t}, \\
D_{t}^{\mathrm{T}}=Z_{t}^{\mathrm{T}} K_{t}^{\theta}-I_{t},
\end{gathered}
$$

with $D_{t}^{\mathrm{T}} \geq 0$, where $\delta>0$ is the depreciation rate on physical capital. Firms in the F traded-goods sector choose investment, $\hat{I}_{t}$, to solve an analogous problem. Notice that firms do not have the option of financing additional investment through the issuance of corporate debt or additional equity. Additional investment can only be undertaken at the expense of current dividends (which must be non-negative).

The production of nontraded goods does not require any capital. The output of nontraded goods by representative firms in countries $\mathrm{H}$ and $\mathrm{F}$ is given by

$$
Y_{t}^{\mathrm{N}}=\kappa Z_{t}^{\mathrm{N}} \quad \text { and } \quad \hat{Y}_{t}^{\mathrm{N}}=\kappa \hat{Z}_{t}^{\mathrm{N}}
$$

where $\kappa>0$ is a constant. $Z_{t}^{\mathrm{N}}$ and $\hat{Z}_{t}^{\mathrm{N}}$ denote the period $-t$ state of nontraded good productivity in countries $\mathrm{H}$ and $\mathrm{F}$ respectively. The output of nontraded goods can only be consumed by domestic households. The resulting proceeds are then distributed in the form of dividends to owners of equity. As above, we normalize 
the number of shares issued by the representative firms to unity, so period- $t$ dividends are $D_{t}^{\mathrm{N}}=Y_{t}^{\mathrm{N}}$ for $\mathrm{H}$

firms and $\hat{D}_{t}^{\mathrm{N}}=\hat{Y}_{t}^{\mathrm{N}}$ for $\mathrm{F}$ firms. We denote the ex-dividend price of a share in the representative $\mathrm{H}$ and $\mathrm{F}$ firm, measured in terms of nontraded goods, as $P_{t}^{\mathrm{N}}$ and $\hat{P}_{t}^{\mathrm{N}}$ respectively.

Productivity in the traded and nontraded good sectors is governed by an exogenous productivity process. In particular, we assume that the vector $z_{t} \equiv\left[\ln Z_{t}^{\mathrm{T}}, \ln \hat{Z}_{t}^{\mathrm{T}}, \ln Z_{t}^{\mathrm{N}}, \ln \hat{Z}_{t}^{\mathrm{N}}\right]^{\prime}$ follows an $\operatorname{AR}(1)$ process:

$$
z_{t}=a z_{t-1}+e_{t}
$$

where $e_{t}$ is a $(4 \times 1)$ vector of i.i.d. normally distributed, mean zero shocks with covariance $\Omega_{e}$.

\subsection{Households}

Each country is populated by a continuum of households who have identical preferences over the consumption of traded and nontraded goods. The preferences of a representative household in country $\mathrm{H}$ are given by

$$
\mathbb{U}_{t}=\mathbb{E}_{t} \sum_{i=0}^{\infty} \beta^{i} U\left(C_{t+i}\right)
$$

where $0<\beta<1$ is the discount factor, and $U($.$) is the period sub-utility function. \mathbb{E}_{t}$ denotes expectations conditioned on period- $t$ information. We assume that $U\left(C_{t}\right)=\ln C_{t}$ where aggregate consumption, $C_{t}$, is defined by a CES aggregator over the consumption of traded and nontraded goods, $C_{t}^{\mathrm{T}}$ and $C_{t}^{\mathrm{N}}$ :

$$
C_{t} \equiv\left[\lambda_{\mathrm{T}}^{1-\phi}\left(C^{\mathrm{T}}\right)^{\phi}+\lambda_{\mathrm{N}}^{1-\phi}\left(C^{\mathrm{N}}\right)^{\phi}\right]^{1 / \phi}
$$

with $\phi<1 . \lambda_{\mathrm{T}}$ and $\lambda_{\mathrm{N}}$ are the weights the household assigns to traded and nontraded consumption respectively. Preferences for households in country F are similarly defined in terms of foreign consumption of traded and nontraded goods, $\hat{C}_{t}^{\mathrm{T}}$ and $\hat{C}_{t}^{\hat{\mathrm{N}}}$.

The array of financial assets available to households differs according to the degree of financial integration. Under FA, households can hold their wealth in the form of equity issued by domestic firms in the traded and nontraded goods sectors (hereafter denoted traded and nontraded equity). Under LI, households can hold internationally traded bonds in addition to their domestic equity holdings. The third case we consider is HI. Here households can hold domestic equity, international bonds and equity issued by firms in the foreign traded-goods sector (hereafter foreign traded equity).

The household's budget constraint associated with each of these different financial structures can be written in a simple common form. In the case of the representative $\mathrm{H}$ household, we write

$$
W_{t+1}=R_{t+1}^{\mathrm{W}}\left(W_{t}-C_{t}^{\mathrm{T}}-Q_{t}^{\mathrm{N}} C_{t}^{\mathrm{N}}\right)
$$

where $Q_{t}^{\mathrm{N}}$ is the relative price of $\mathrm{H}$ nontradables in terms of tradables. $R_{t+1}^{\mathrm{W}}$ is the (gross) return on wealth between period $t$ and $t+1$, where wealth, $W_{t}$, is measured in terms of tradables. The return on wealth depends on how the household allocates wealth across the available array of financial assets, and on the 
realized returns on those assets. In the HI case, the return is given by

$$
R_{t+1}^{\mathrm{W}}=R_{t}+\alpha_{t}^{\mathrm{T}}\left(R_{t+1}^{\mathrm{T}}-R_{t}\right)+\alpha_{t}^{\hat{\mathrm{T}}}\left(R_{t+1}^{\hat{\mathrm{T}}}-R_{t}\right)+\alpha_{t}^{\mathrm{N}}\left(R_{t+1}^{\mathrm{N}}-R_{t}\right)
$$

where $R_{t}$ is the return on bonds, $R_{t+1}^{\mathrm{T}}$ and $R_{t+1}^{\hat{\mathrm{r}}}$ are the returns on $\mathrm{H}$ and F traded equity, and $R_{t+1}^{\mathrm{N}}$ is the return on $\mathrm{H}$ nontraded equity. The fraction of wealth held in $\mathrm{H}$ and $\mathrm{F}$ traded equity and $\mathrm{H}$ nontraded equity are $\alpha_{t}^{\mathrm{T}}, \alpha_{t}^{\hat{\mathrm{T}}}$ and $\alpha_{t}^{\mathrm{N}}$ respectively. In the LI case, $\mathrm{H}$ households cannot hold F traded equity, so $\alpha_{t}^{\hat{\mathrm{T}}}=0$. Under FA, households can only hold domestic equity, so $\alpha_{t}^{\hat{\mathrm{T}}}=0$ and $\alpha_{t}^{\mathrm{T}}+\alpha_{t}^{\mathrm{N}}=1$.

The budget constraint for F households is similarly represented by

$$
\hat{W}_{t+1}=\hat{R}_{t+1}^{\mathrm{W}}\left(\hat{W}_{t}-\hat{C}_{t}^{\mathrm{T}}-\hat{Q}_{t}^{\mathrm{N}} \hat{C}_{t}^{\hat{\mathrm{N}}}\right)
$$

with

$$
\hat{R}_{t+1}^{\mathrm{W}}=R_{t}+\hat{\alpha}_{t}^{\mathrm{T}}\left(\hat{R}_{t+1}^{\mathrm{T}}-R_{t}\right)+\hat{\alpha}_{t}^{\hat{\mathrm{T}}}\left(\hat{R}_{t+1}^{\hat{\mathrm{T}}}-R_{t}\right)+\hat{\alpha}_{t}^{\hat{\mathrm{N}}}\left(\hat{R}_{t+1}^{\hat{\mathrm{N}}}-R_{t}\right),
$$

where $\hat{R}_{t+1}^{\mathrm{T}}$, and $\hat{R}_{t+1}^{\hat{\mathrm{T}}}$ denote the returns on H and F traded equity, and $\hat{R}_{t+1}^{\hat{\mathrm{N}}}$ is the return on F nontraded equity. Although these returns are also measured in terms of tradables, they can differ from the returns available to $\mathrm{H}$ households. In particular, the returns on nontraded equity received by F households, $\hat{R}_{t+1}^{\hat{\mathrm{v}}}$, will in general differ from the returns received by $\mathrm{H}$ households because the assets are not internationally traded. Arbitrage will equalize returns in other cases. In particular, if bonds are traded, the interest received by $\mathrm{H}$ and F households must be the same as (8) and (10) show. Similarly, arbitrage will equalize the returns on traded equity in the case of LI and HI so that $R_{t+1}^{\mathrm{T}}=\hat{R}_{t+1}^{\mathrm{T}}$ and $R_{t+1}^{\hat{\mathrm{T}}}=\hat{R}_{t+1}^{\hat{\mathrm{T}}}$.

\subsection{Market Clearing}

The market clearing requirements of the model are most easily stated if we normalize the national populations to unity, as well as the population of firms in the traded and nontraded sectors. Output and consumption of traded and nontraded goods can now be represented by the output and consumption of representative households and firms. In particular, the market clearing conditions in the nontraded sector of each country are given by

$$
C_{t}^{\mathrm{N}}=Y_{t}^{\mathrm{N}}, \quad \text { and } \quad \hat{C}_{t}^{\hat{\mathrm{N}}}=\hat{Y}_{t}^{\mathrm{N}}
$$

Recall that firms in the nontraded sector pay dividends to their shareholders with the proceeds from the sale of nontradables to households. Thus, market clearing in the nontraded sector also implies that

$$
D_{t}^{\mathrm{N}}=Y_{t}^{\mathrm{N}}, \quad \text { and } \quad \hat{D}_{t}^{\mathrm{N}}=\hat{Y}_{t}^{\mathrm{N}} .
$$

Next, we turn to market clearing in financial markets. Let $A_{t}^{\mathrm{T}}, A_{t}^{\hat{\mathrm{T}}}$ and $A_{t}^{\mathrm{N}}$ denote the number of shares of $\mathrm{H}$ traded, $\mathrm{F}$ traded and $\mathrm{H}$ nontraded equities held by $\mathrm{H}$ households between the end of periods $t$ and $t+1$. $\mathrm{F}$ household holdings in H traded, F traded and F nontraded equities are represented by $\hat{A}_{t}^{\mathrm{T}}, \hat{A}_{t}^{\hat{\mathrm{T}}}$ and $\hat{A}_{t}^{\hat{\mathrm{N}}}$. H and F household holdings of bonds between the end of periods $t$ and $t+1$ are denoted by $B_{t}$ and $\hat{B}_{t}$. Household demand for equity and bonds are determined by their optimal choice of portfolio shares (i.e., $\alpha_{t}^{\mathrm{T}}, \alpha_{t}^{\hat{\mathrm{T}}}$ and $\alpha_{t}^{\mathrm{N}}$ for H households, and $\hat{\alpha}_{t}^{\mathrm{T}}, \hat{\alpha}_{t}^{\hat{\mathrm{T}}}$ and $\hat{\alpha}_{t}^{\hat{\mathrm{N}}}$ for F households) described below. We assume that bonds are in zero 
net supply.

The market clearing conditions in financial markets vary according to the degree of financial integration. Under FA, households can only hold the equity issued by domestically located firms, so the equity market clearing conditions are

$$
\begin{array}{rllll}
\text { home: } & 1=A_{t}^{\mathrm{T}}, & 0=A_{t}^{\hat{\mathrm{T}}}, & \text { and } & 1=A_{t}^{\mathrm{N}}, \\
\text { FOREIGN: } & 0=\hat{A}_{t}^{\mathrm{T}}, & 1=\hat{A}_{t}^{\hat{\mathrm{T}}}, & \text { and } & 1=\hat{A}_{t}^{\hat{\mathrm{N}}},
\end{array}
$$

while bond market clearing requires that

$$
0=B_{t}, \quad \text { and } \quad 0=\hat{B}_{t}
$$

Notice that FA rules out the possibility of international borrowing or lending, so neither country can run at positive or negative trade balance. Domestic consumption of tradables must therefore equal the fraction of traded output not allocated to investment. Hence, market clearing under FA also implies that

$$
D_{t}^{\mathrm{T}}=C_{t}^{\mathrm{T}}=Y_{t}^{\mathrm{T}}-I_{t}, \quad \text { and } \quad \hat{D}_{t}^{\mathrm{T}}=\hat{C}_{t}^{\mathrm{T}}=\hat{Y}_{t}^{\mathrm{T}}-\hat{I}_{t}
$$

Under LI, households can hold bonds in addition to domestic equity holdings. In this case, equity market clearing requires the conditions in (13), but the bond market clearing condition becomes

$$
0=B_{t}+\hat{B}_{t}
$$

The bond market can now act as the medium for international borrowing and lending, so there is no longer a balanced trade requirement restricting dividends. Instead, the traded goods market clearing condition becomes

$$
D_{t}^{\mathrm{T}}+\hat{D}_{t}^{\mathrm{T}}=C_{t}^{\mathrm{T}}+\hat{C}_{t}^{\mathrm{T}}=Y_{t}^{\mathrm{T}}+\hat{Y}_{t}^{\mathrm{T}}-I_{t}-\hat{I}_{t}
$$

Under HI, households have access to domestic equity, international bonds and equity issued by firms in the foreign traded sector. In this case market clearing in equity markets requires that

$$
\begin{aligned}
& \text { TRADED : } \quad 1=A_{t}^{\mathrm{T}}+\hat{A}_{t}^{\mathrm{T}}, \quad \text { and } \quad 1=A_{t}^{\hat{\mathrm{T}}}+\hat{A}_{t}^{\hat{\mathrm{T}}}, \\
& \text { NONTRADED : } 1=A_{t}^{\mathrm{N}}, \quad \text { and } \quad 1=\hat{A}_{t}^{\hat{\mathrm{N}}} \text {. }
\end{aligned}
$$

Market clearing in the bond market continues to require condition (16) so traded dividends satisfy (17). In this case international borrowing and lending takes place via trade in international bonds and the equity of $\mathrm{H}$ and $\mathrm{F}$ firms producing traded goods. 


\section{Equilibrium}

An equilibrium in our world comprises a set of asset prices and relative goods prices that clear markets given the state of productivity, the optimal investment decisions of firms producing traded goods, and the optimal consumption, savings and portfolios decisions of households. In this section, we first characterize the solutions to the optimization problems facing households and firms. We then provide an overview of how we find the equilibrium.

Consider the problem facing a H household under HI. The household chooses consumption of traded and nontraded goods, $C_{t}^{\mathrm{T}}$ and $C_{t}^{\mathrm{N}}$, and portfolio shares for equity in $\mathrm{H}$ and $\mathrm{F}$ firms producing tradables and $\mathrm{H}$ firms producing nontradables, $\alpha_{t}^{\mathrm{T}}, \alpha_{t}^{\hat{\mathrm{r}}}$ and $\alpha_{t}^{\mathrm{N}}$, to maximize expected utility (5) subject to $(7)$ and (8) given current equity prices, $\left\{P_{t}^{\mathrm{T}} P_{t}^{\hat{\mathrm{T}}}, P_{t}^{\mathrm{N}}, \hat{P}_{t}^{\mathrm{N}}\right\}$, the interest rate on bonds, $R_{t}$, and the relative price of nontradables, $\left\{Q_{t}^{\mathrm{N}}, \hat{Q}_{t}^{\mathrm{N}}\right\}$. The first-order conditions are

$$
\begin{aligned}
Q_{t}^{\mathrm{N}} & =\frac{\partial U / \partial C_{t}^{\mathrm{N}}}{\partial U / \partial C_{t}^{\mathrm{T}}}, \\
1 & =\mathbb{E}_{t}\left[M_{t+1} R_{t+1}^{\mathrm{T}}\right], \\
1 & =\mathbb{E}_{t}\left[M_{t+1} R_{t+1}^{\mathrm{N}}\right], \\
1 & =\mathbb{E}_{t}\left[M_{t+1} R_{t}\right], \\
1 & =\mathbb{E}_{t}\left[M_{t+1} R_{t+1}^{\hat{\mathrm{T}}}\right],
\end{aligned}
$$

where $M_{t+1} \equiv \beta\left(\partial U / \partial C_{t+1}^{\mathrm{T}}\right) /\left(\partial U / \partial C_{t}^{\mathrm{T}}\right)$ is the discounted intertemporal marginal rate of substitution (IMRS) between the consumption of tradables in period $t$ and period $t+1$. Condition (19a) equates the relative price of nontradables to the marginal rate of substitution between the consumption of tradables and nontradables. Under FA, consumption and portfolio decisions are completely characterized by (19a) (19c). When households are given access to international bonds under LI, there is an extra dimension to the portfolio choice problem facing households so (19d) is added to the set of first-order conditions. Under HI, all the conditions in (19) are needed to characterize optimal H households' behavior. An analogous set of conditions characterize the behavior of $\mathrm{F}$ households.

It is important to note that all the returns in (19) are measured in terms of tradables. In particular, the return on the equity of firms producing traded goods in the $\mathrm{H}$ and $\mathrm{F}$ counties held by $\mathrm{H}$ investors are

$$
R_{t+1}^{\mathrm{T}}=\left(P_{t+1}^{\mathrm{T}}+D_{t+1}^{\mathrm{T}}\right) / P_{t}^{\mathrm{T}}, \quad \text { and } \quad R_{t+1}^{\hat{\mathrm{T}}}=\left(\hat{P}_{t+1}^{\mathrm{T}}+\hat{D}_{t+1}^{\mathrm{T}}\right) / \hat{P}_{t}^{\mathrm{T}}
$$

The returns on equity producing nontraded goods differ across countries. In particular, the return on equity for $\mathrm{H}$ households is

$$
R_{t+1}^{\mathrm{N}}=\left\{\left(P_{t+1}^{\mathrm{N}}+D_{t+1}^{\mathrm{N}}\right) / P_{t}^{\mathrm{N}}\right\}\left\{Q_{t+1}^{\mathrm{N}} / Q_{t}^{\mathrm{N}}\right\},
$$

while for F households the return is

$$
\hat{R}_{t+1}^{\hat{N}}=\left\{\left(\hat{P}_{t+1}^{\mathrm{N}}+\hat{D}_{t+1}^{\mathrm{N}}\right) / \hat{P}_{t}^{\mathrm{N}}\right\}\left\{\hat{Q}_{t+1}^{\mathrm{N}} / \hat{Q}_{t}^{\mathrm{N}}\right\}
$$


where $\hat{Q}_{t}^{\mathrm{N}}$ is the relative price of nontradables in country F.

The returns $R_{t+1}^{\mathrm{N}}$ and $\hat{R}_{t+1}^{\hat{\mathrm{N}}}$ differ from each other for two reasons: First, international productivity differentials in the nontraded sectors will create differences in returns measured in terms of nontradables. These differences will affect returns via the first term on the right hand side of (21) and (22). Second, international differences in the dynamics of relative prices $Q_{t}^{\mathrm{N}}$ and $\hat{Q}_{t}^{\mathrm{N}}$ will affect returns via the second term in each equation. These differences arise quite naturally in equilibrium as the result of productivity shocks in either the traded or nontraded sectors.

Variations in the relative prices of nontraded goods also drive the real exchange rate. Since the price of traded goods is normalized to one, the utility-based price indices in the $\mathrm{H}$ and $\mathrm{F}$ countries are

$$
Q_{t}=\left[\lambda_{T}+\lambda_{N}\left(Q_{t}^{\mathrm{N}}\right)^{\frac{\phi}{\phi-1}}\right]^{\frac{\phi-1}{\phi}} \quad \text { and } \quad \hat{Q}_{t}=\left[\hat{\lambda}_{T}+\hat{\lambda}_{N}\left(\hat{Q}_{t}^{\mathrm{N}}\right)^{\frac{\phi}{\phi-1}}\right]^{\frac{\phi-1}{\phi}}
$$

so the real exchange rate, defined as the ratio of national price indices, is

$$
\mathcal{E}_{t} \equiv \frac{\hat{Q}_{t}}{Q_{t}}=\left\{\frac{\hat{\lambda}_{T}+\hat{\lambda}_{N}\left(\hat{Q}_{t}^{\mathrm{N}}\right)^{\frac{\phi}{\phi-1}}}{\lambda_{T}+\lambda_{N}\left(Q_{t}^{\mathrm{N}}\right)^{\frac{\phi}{\phi-1}}}\right\}^{\frac{\phi-1}{\phi}}
$$

The returns on equity shown in (20) - (22) are functions of equity prices, the relative price of nontradables, and the dividends paid by firms. The requirements of market clearing and our specification for the production of nontraded goods implies that nontraded dividends, $D_{t+1}^{\mathrm{N}}$ and $\hat{D}_{t+1}^{\mathrm{N}}$, are exogenous. By contrast, the dividends paid by firms producing traded goods are determined optimally. Recall that $\mathrm{H}$ firms choose real investment $I_{t}$ in period $t$ to maximize the current value of the firm, $D_{t}^{\mathrm{T}}+P_{t}^{\mathrm{T}}$. Combining (19b) with the definition of returns $R_{t+1}^{\mathrm{T}}$ in (20) implies that $P_{t}^{\mathrm{T}}=\mathbb{E}_{t}\left[M_{t+1}\left(P_{t+1}^{\mathrm{T}}+D_{t+1}^{\mathrm{T}}\right)\right]$. This equation identifies the price a $\mathrm{H}$ household would pay for equity in the firm (after period $-t$ dividends have been paid). Using this expression to substitute for $P_{t}^{\mathrm{T}}$ in the $\mathrm{H}$ firm's investment problem (2) gives the following first-order condition:

$$
1=\mathbb{E}_{t}\left[M_{t+1}\left(\theta Z_{t+1}^{\mathrm{T}}\left(K_{t+1}\right)^{\theta-1}+(1-\delta)\right)\right]
$$

This condition implicitly identifies the optimal level of dividends in period $t$ because next period's capital depends on current capital, productivity and dividend payments: $K_{t+1}=(1-\delta) K_{t}+Z_{t}^{\mathrm{T}} K_{t}^{\theta}-D_{t}^{\mathrm{T}}$. Dividends on the equity of $\mathrm{F}$ firms producing traded goods are similarly determined by

$$
1=\mathbb{E}_{t}\left[\hat{M}_{t+1}\left(\theta \hat{Z}_{t+1}^{\mathrm{T}}\left(\hat{K}_{t+1}\right)^{\theta-1}+(1-\delta)\right)\right]
$$

where $\hat{M}_{t+1}$ is the IMRS for traded goods in country F, and $\hat{K}_{t+1}=(1-\delta) \hat{K}_{t}+\hat{Z}_{t}^{\mathrm{T}} \hat{K}_{t}^{\theta}-\hat{D}_{t}^{\mathrm{T}}$.

The dividend policies implied by (24) and (25) maximize the value of each firm from the perspective of domestic shareholders. For example, the stream of dividends implied by (24) maximizes the value of $\mathrm{H}$ firms producing traded goods for households in country $\mathrm{H}$ because the firm uses $M_{t+1}$ to value future dividends. This is an innocuous assumption under financial autarky and partial integration because domestic households must hold all the firm's equity. Under full integration, however, foreign households have the opportunity to 
hold the H firm's equity so the firm's dividend policy need not maximize the value of equity to all shareholders. In particular, since markets are incomplete even under full integration, the IMRS for $\mathrm{H}$ and $\mathrm{F}$ households will differ, so F households holding domestic equity will generally prefer a different dividend stream from the one implied by (24). In short, the dividend streams implied by (24) and (25) incorporate a form of home bias because they focus exclusively on the interests of domestic shareholders. ${ }^{2}$

We can now summarize the equilibrium actions of firms and households. At the beginning of period $t$, firms in the traded-goods sector observe the new level of productivity and decide on the amount of real investment to undertake. This decision determines dividend payments $D_{t}^{\mathrm{T}}$ and $\hat{D}_{t}^{\mathrm{T}}$ as functions of existing productivity, physical capital, expectations regarding future productivity and the IMRS of domestic shareholders. Firms in the nontraded sectors have no real investment decision to make so in equilibrium $D_{t}^{\mathrm{N}}$ and $\hat{D}_{t}^{\mathrm{N}}$ depend only on current productivity. At the same time, households begin period $t$ with a portfolio of financial assets (chosen at the end of the previous period). Under FA the menu of assets is restricted to domestic equities, under LI households may hold domestic equities and bonds, and under HI the menu contains domestic equity, foreign traded equity and bonds. Households receive dividend payments from firms according to the composition of their portfolios. They then make consumption and new portfolio decisions based on the market-clearing relative price for nontradables, and the market-clearing prices for equity. The first-order conditions in (19) implicitly identify the decisions made by $\mathrm{H}$ households. The decisions made by $\mathrm{F}$ households are characterized by an analogous set of equations. The portfolio shares determined in this manner will depend on household expectations concerning future returns and the IMRS. As equations (20) - (22) show, equity returns are functions of current equity prices and future dividends and prices, so expectations regarding the latter will be important for determining how households choose portfolios in period $t$. Current and future consumption decisions also affect period $-t$ portfolio shares through the IMRS. Households' demand for financial assets in period $t$ follow from decisions on consumption and the portfolio shares in a straightforward manner. In the case of $\mathrm{HI}$, the demand for each asset from $\mathrm{H}$ and $\mathrm{F}$ households is

$\begin{array}{lll} & \text { H households } & \text { F households } \\ \text { H TRADED EQUity: } & A_{t}^{\mathrm{T}}=\alpha_{t}^{\mathrm{T}} W_{t}^{\mathrm{C}} / P_{t}^{\mathrm{T}}, & \hat{A}_{t}^{\mathrm{T}}=\hat{\alpha}_{t}^{\mathrm{T}} \hat{W}_{t}^{\mathrm{C}} / P_{t}^{\mathrm{T}}, \\ \text { F TRADED EQUiTY: } & A_{t}^{\hat{\mathrm{T}}}=\alpha_{t}^{\hat{\mathrm{T}}} W_{t}^{\mathrm{C}} / P_{t}^{\hat{\mathrm{T}}}, & \hat{A}_{t}^{\hat{\mathrm{T}}}=\hat{\alpha}_{t}^{\hat{\mathrm{T}}} \hat{W}_{t}^{\mathrm{C}} / P_{t}^{\hat{\mathrm{T}}}, \\ \text { NONTRADED EQUiTY: } & A_{t}^{\mathrm{N}}=\alpha_{t}^{\mathrm{N}} W_{t}^{\mathrm{C}} / Q_{t}^{\mathrm{N}} P_{t}^{\mathrm{N}}, & \hat{A}_{t}^{\mathrm{N}}=\hat{\alpha}_{t}^{\hat{\mathrm{N}}} \hat{W}_{t}^{\mathrm{C}} / Q_{t}^{\hat{\mathrm{N}}} P_{t}^{\hat{\mathrm{N}}}, \\ \text { BONDS } & B_{t}=\alpha_{t}^{\mathrm{B}} W_{t}^{\mathrm{C}} R_{t}, & \hat{B}_{t}=\hat{\alpha}_{t}^{\mathrm{B}} \hat{W}_{t}^{\mathrm{C}} R_{t},\end{array}$

where $W_{t}^{\mathrm{C}} \equiv W_{t}-C_{t}^{\mathrm{T}}-Q_{t}^{\mathrm{N}} C_{t}^{\mathrm{N}}$ and $\hat{W}_{t}^{\mathrm{C}} \equiv \hat{W}_{t}-\hat{C}_{t}^{\mathrm{T}}-\hat{Q}_{t}^{\mathrm{N}} \hat{C}_{t}^{\hat{\mathrm{N}}}$ denote period- $t$ wealth net of consumption expenditure with $\alpha_{t}^{\mathrm{B}} \equiv 1-\alpha_{t}^{\mathrm{T}}-\alpha_{t}^{\hat{\mathrm{T}}}-\alpha_{t}^{\mathrm{N}}$ and $\hat{\alpha}_{t}^{\mathrm{B}} \equiv 1-\hat{\alpha}_{t}^{\mathrm{T}}-\hat{\alpha}_{t}^{\hat{\mathrm{T}}}-\hat{\alpha}_{t}^{\mathrm{N}}$. Equation (26) shows that asset demands depend on expected future returns and risk via optimally chosen portfolio shares, $\boldsymbol{\alpha}_{t}$, accumulated net wealth $W_{t}^{\mathrm{C}}$ and $\hat{W}_{t}^{\mathrm{C}}$, and current asset prices (i.e., $P_{t}^{\mathrm{T}}, \hat{P}_{t}^{\mathrm{T}}, P_{t}^{\mathrm{N}}$ and $\hat{P}_{t}^{\mathrm{N}}$ for equity, and $1 / R_{t}$ for bonds).

Finding the equilibrium in this model is conceptually straightforward. All that is required are the time series processes for equity prices $\left\{P_{t}^{\mathrm{T}}, \hat{P}_{t}^{\mathrm{T}}, P_{t}^{\mathrm{N}}\right.$ and $\left.\hat{P}_{t}^{\mathrm{N}}\right\}$, the relative prices of nontradables $\left\{Q_{t}^{\mathrm{N}}\right.$ and $\left.\hat{Q}_{t}^{\mathrm{N}}\right\}$, and

\footnotetext{
${ }^{2}$ We have also studied the properties of the HI equilibrium in a version of the model where firms use a geometric average of the $\mathrm{H}$ and F IMRS (i.e. $M_{t+1}^{1 / 2} \hat{M}_{t+1}^{1 / 2}$ ) to value future dividends. The properties of this equilibrium turned out to be very similar to those we report below using the domestic IMRS, so we stick with the simpler specification.
} 
interest rate on bonds $R_{t}$, that clear markets given the optimal behavior of firms and households. Finding these time series in practice is complicated by the need to completely characterize how firms and households behave. When markets are complete, this complication can be circumvented by finding the equilibrium allocations as the solution of an appropriate social planning problem and then deriving the price and interest rates processes that support these allocations when decision-making is decentralized. This solution method is inapplicable in our model. When markets are incomplete, as they are under FA, LI, and HI, there is no way to formulate a social planning problem that will provide the equilibrium allocation of the decentralized market economy. To solve the model we must therefore characterize the optimal behavior of firms and households for a wide class of price and returns' processes, and then use the implied allocations in conjunction with the market clearing conditions to find the particular set of price and returns' processes that clear markets. The next section describes this procedure in detail. Readers wishing to skip straight to our analysis of the model, may proceed directly to Section 5 .

\section{The Solution Procedure}

Our solution procedure comprises three steps:

1. Conjecture the identity and time-series process describing the equilibrium dynamics of the state variables and prices.

2. Use the conjecture from Step 1 to characterize the optimal choice of investment/dividends by firms, and the optimal choice of consumption and asset demands by households.

3. Combine the aggregate implications of the firms' and households' decisions with the requirements of market clearing to determine the properties of equilibrium prices and returns. Check that these properties match the Step 1 conjecture.

These steps involve several novel aspects to account for the presence of portfolio choice and the absence of complete markets. We now describe each step in detail.

\subsection{The Three Steps}

Step 1 We begin by identifying the set of predetermined variables whose values are sufficient to determine the state of the economy at each point in time. For this purpose, let $x_{t} \equiv\left[z_{t}, k_{t}, \hat{k}_{t}, w_{t}, \hat{w}_{t}\right]^{\prime}$ where $k_{t} \equiv$ $\ln \left(K_{t} / K\right), \hat{k}_{t} \equiv \ln \left(\hat{K}_{t} / K\right), w_{t} \equiv \ln \left(W_{t} / W_{0}\right)$ and $\hat{w}_{t} \equiv \ln \left(\hat{W}_{t} / \hat{W}_{0}\right)$ with the steady state capital stock denoted by $K$, and initial level of н (F) wealth denoted by $W_{0}\left(\hat{W}_{0}\right)$. Hereafter we denote steady state values by the absence of a $t$ subscript. We conjecture that $x_{t}$ follows

$$
x_{t+1}=\Phi_{0}+\left(I-\Phi_{1}\right) x_{t}+\Phi_{2} \tilde{x}_{t}+u_{t+1}
$$

where $\tilde{x}_{t} \equiv \operatorname{vec}\left(x_{t} x_{t}^{\prime}\right), \mathbb{E}\left(u_{t+1} \mid x_{t}\right)=0$, and $\mathbb{E}\left(u_{t+1} u_{t+1}^{\prime} \mid x_{t}\right)=\Omega_{0}+\Omega_{1} x_{t} x_{t}^{\prime} \Omega_{1}^{\prime}$ for conformable matrices $\Phi_{i}$ and $\Omega_{i}$. This conjecture includes two important features: First, it allows lagged squares and cross-products 
of period $-t$ variables to affect period $-(t+1)$ values via the $\Phi_{2}$ matrix. Second, the vector of innovations, $u_{t+1}$, is conditionally heteroskedastic (i.e., the covariance varies with the cross-products in $x_{t}$ ). Recall that the productivity process is linear and homoskedastic, so the elements of $\Phi_{2}$ and $\Omega_{1}$ corresponding to $z_{t}$ are zero. Nevertheless, as we discuss below, the equilibrium processes for wealth will display both non-linear dependency and conditional heteroskedasticity when market are incomplete. We must therefore allow for these features when conjecturing how wealth behaves in equilibrium.

As we shall see, the optimizing decisions of firms and households depend on the distribution of future returns, prices, capital and wealth. To characterize this distribution, we need to derive the implications of (27) for the moments of $x_{t+h}$ conditioned on $x_{t}$ and $\tilde{x}_{t}$. For this purpose, we first define the state vector $X_{t}$ that includes a constant, $x_{t}$ and the cross-product vector $\tilde{x}_{t}$, i.e. $X_{t} \equiv\left[\begin{array}{lll}1, & x_{t}^{\prime}, & \tilde{x}_{t}^{\prime}\end{array}\right]^{\prime}$. We then derive the approximate dynamics of $X_{t}$ implied by (27) as

$$
X_{t+1}=\mathbb{A} X_{t}+U_{t+1}
$$

where $U_{t+1}$ is a vector of shocks with $\mathbb{E}\left[U_{t+1} \mid X_{t}\right]=0$, and $\mathbb{E}\left[U_{t+1} U_{t+1}^{\prime} \mid X_{t}\right]=\mathbb{S}\left(X_{t}\right)$. Equation (28) represents a second-order approximation to the dynamics implied by (27). In other words, we ignore all terms involving elements of $\tilde{x}_{t} x_{t}^{\prime}$ in deriving (28) from (27). Evans and Hnatkovska (2006) describe the derivation of (28) from (27) in detail and show that the approximation error in (28) disappears in the continuous time limit when the $u_{t}$ shocks represent realizations of Brownian motion. More importantly, as the Appendix shows, all the elements of the matrix $\mathbb{A}$ and the conditional covariance function $\mathbb{S}($.$) can be computed from$ the $\Phi_{i}$ and $\Omega_{i}$ matrices in (27). Thus, (28) can be viewed as representation for the dynamics of the complete state vector, $X_{t}$, based on the conjectured dynamics for $x_{t}$ in (27).

Our solution procedure expresses all the endogenous variables in the model as linear combinations of $X_{t}$. Thus, for any two variables $a_{t}$ and $b_{t}$, we find the vectors $\pi_{a}$ and $\pi_{b}$ such that $a_{t}=\pi_{a} X_{t}$ and $b_{t}=\pi_{b} X_{t}$. In Steps 2 and 3 below we derive restrictions from the optimality and market clearing conditions sufficient to identify the $\pi$ vectors for all the endogenous variables. At this stage, our concern is how to compute the first and second moments given the $\pi$ vectors. This is simply accomplished. In particular, for any variables $a_{t}$ and $b_{t},(28)$ implies that

$$
\begin{aligned}
\mathbb{E}\left[a_{t+h} \mid X_{t}\right] & =\pi_{a} \mathbb{A}^{h} X_{t}, \quad \text { and } \\
\mathbb{C V}\left[a_{t+1}, b_{t+1} \mid X_{t}\right] & =\mathcal{A}\left(\pi_{a}, \pi_{b}\right) X_{t}
\end{aligned}
$$

The expression for $E\left[a_{t+h} \mid X_{t}\right]$ follows in the standard way from the linearity of the process in (28). The second expression shows that under the second-order approximation implicit in (28), the conditional covariance between $a_{t+1}$ and $b_{t+1}$ depends linearly on $X_{t}$. The form of this linear dependence is determined by the $\mathcal{A}(.,$.$) vector which has elements that depend on the vectors \pi_{a}, \pi_{b}$ and the parameters of the $X_{t}$ process. Thus, both the conditional first and second moments of any variables in the model can be (approximately) expressed as linear functions of $X_{t}$. The product of $a_{t}$ and $b_{t}$ can be similarly approximated to second-order by

$$
a_{t} b_{t}=\mathcal{B}\left(\pi_{a}, \pi_{b}\right) X_{t}
$$


where $\mathcal{B}(.,$.$) is another vector with elements that depend on \pi_{a}, \pi_{b}$ and the parameters of the $X_{t}$ process.

We make extensive use of (29) - (31) in Steps 2 and 3 below. For the special case where $a_{t}$ and $b_{t}$ are the $i$ and $j$ 'th. elements of $x_{t}, \pi_{a}=\imath_{a}$ and $\pi_{b}=\imath_{b}$ where $\imath_{\varkappa}$ is a vector of zeros and a one that picks out variable $\varkappa$ from $X_{t}$. In this special case, $\mathcal{B}(.,$.$) is a vector that selects the first instance of a_{t} b_{t}$ in the $X_{t}$ vector and $\mathcal{A}(.,$.$) equals \left[\Omega_{0}^{i, j}, \quad 0, \quad \Omega_{1}^{j, .} \otimes \Omega_{1}^{i, .}\right]$ where $\Omega_{0}^{i, j}$ denotes the $i, j^{\prime}$ th. element of $\Omega_{0}$ and $\Omega_{1}^{i, .}$ denotes the $i$ 'th. row of $\Omega_{1}$. The precise form for $\mathcal{A}(.,$.$) and \mathcal{B}(.,$.$) when \pi_{a} \neq \imath_{a}$ and $\pi_{b} \neq \imath_{b}$ are presented in the Appendix.

To this point we have derived the second-order implications for the behavior of linear combinations of the state vector $X_{t}$ given a conjecture about the dynamics of $x_{t}$ in (27). To complete step 1 , we now posit that equilibrium log prices and the log interest rate are linearly related to the state vector. Let lowercase letters denote the $\log$ transformation of the corresponding variable (e.g. $r_{t} \equiv \ln R_{t}, q_{t}^{\mathrm{N}} \equiv \ln \left(Q_{t}^{\mathrm{N}}\right)$ ). We conjecture that in equilibrium

$$
\begin{aligned}
& p_{t}^{\mathrm{T}}=\pi_{p}^{\mathrm{T}} X_{t}, \quad p_{t}^{\mathrm{N}}=\pi_{p}^{\mathrm{N}} X_{t}, \quad q_{t}^{\mathrm{N}}=\pi_{q}^{\mathrm{N}} X_{t}, \\
& p_{t}^{\hat{\mathrm{N}}}=\pi_{p}^{\hat{\mathrm{T}}} X_{t}, \quad p_{t}^{\hat{\mathrm{N}}}=\pi_{p}^{\hat{\mathrm{N}}} X_{t}, \quad q_{t}^{\hat{\mathrm{N}}}=\pi_{q}^{\hat{\mathrm{N}}} X_{t}, \quad \text { and } \quad r_{t}=\pi_{r} X_{t},
\end{aligned}
$$

for some $\pi$ vectors of coefficients determined below.

Step 2 We now use our step 1 conjecture to derive the optimal behavior of households and firms. In particular, our aim is to show how the optimal choice of dividends by firms, and the optimal choice of consumption and portfolios by households can be related to the state vector $X_{t}$. For illustrative purposes, we focus on the behavior of $\mathrm{H}$ firms and households under HI.

Characterizing the behavior of firms is straightforward. Recall that market clearing ensures that dividends in the nontraded sector equal output, which is exogenously determined. Hence the dividends issued by nontraded firms are proportional to productivity so in logs, $d_{t}^{\mathrm{N}}=\ln \kappa+z_{t}^{\mathrm{N}}=\pi_{d}^{\mathrm{N}} X_{t}$. In the traded sector, dividends are chosen to maximize shareholder value of the firm. According to our Step 1 conjecture, $X_{t}$ summarizes all relevant information about the state of the economy in period $t$. This means the period $-t$ expectations by firms and households are equal to the expectations conditioned on $X_{t}$. Using this fact, a log-normal approximation to the traded firm's first-order condition in (24) gives

$$
\mathbb{E}_{t}\left[r_{t+1}^{k}\right]=r_{t}-\frac{1}{2} \mathbb{V}_{t}\left(r_{t+1}^{k}\right)-\mathbb{C V}_{t}\left(r_{t+1}^{k}, m_{t+1}\right)
$$

where $r_{t+1}^{k} \equiv \ln \left(\theta Z_{t+1}^{\mathrm{T}}\left(K_{t+1}\right)^{\theta-1}+1-\delta\right)$ is the log return on capital. $\mathbb{E}_{t}[],. \mathbb{V}_{t}($.$) and \mathbb{C V}_{t}(.,$.$) denote$ the expectation, variance and covariance conditioned on $X_{t}$. To find the implications of this expression for dividends, we $\log$-linearize $r_{t+1}^{k}$ and the capital accumulation equation in (2) around the steady state values of $Z_{t}^{\mathrm{T}}$ and $K_{t}$ :

$$
\begin{aligned}
& r_{t+1}^{k}=r^{k}+\psi z_{t+1}^{\mathrm{T}}-(1-\theta) \psi k_{t+1}, \\
& k_{t+1}=\frac{1}{\beta} k_{t}+\frac{\psi}{\beta \theta} z_{t}^{\mathrm{T}}-\frac{\varphi}{\theta \beta}\left(d_{t}^{\mathrm{T}}-d^{\mathrm{T}}\right),
\end{aligned}
$$

where $\psi \equiv 1-\beta(1-\delta)<1$ and $\varphi \equiv \psi-\theta \beta \delta>0$. Since preferences are logarithmic, the IMRS of $\mathrm{H}$ 
households, $M_{t+1}$, is equal to $\beta W_{t} / W_{t+1}$, so in $\operatorname{logs} m_{t+1}=\ln \beta-\Delta w_{t+1}$. The right hand side of (33) can now be rewritten using (34) and the conjectures from Step 1 as $\mathbb{E}_{t} r_{t+1}^{k}=r_{t}-\frac{1}{2} \psi^{2} \mathcal{A}\left(\imath_{z}^{\mathrm{T}}, \imath_{z}^{\mathrm{T}}\right) X_{t}+\psi \mathcal{A}\left(\imath_{z}^{\mathrm{T}}, \imath_{w}\right) X_{t}$. Combining this expression with those in (34) and the fact that $\mathbb{E}\left[z_{t+1}^{\mathrm{T}} \mid X_{t}\right]=\imath_{z}^{\mathrm{T}} \mathbb{A} X_{t}$, gives

$$
d_{t}^{\mathrm{T}}=\left[d^{\mathrm{T}} \imath_{1}+\frac{\theta}{\varphi} \imath_{k}+\frac{\psi}{\varphi} \imath_{z}^{\mathrm{T}}-\frac{\theta \beta}{(1-\theta) \varphi} \imath_{z}^{\mathrm{T}} \mathbb{A}+\frac{\theta \beta}{(1-\theta) \varphi \psi}\left\{\pi_{r}-\frac{1}{2} \psi^{2} \mathcal{A}\left(\imath_{z}^{\mathrm{T}}, \imath_{z}^{\mathrm{T}}\right)+\psi \mathcal{A}\left(\imath_{z}^{\mathrm{T}}, \imath_{w}\right)\right\}\right] X_{t}=\pi_{d}^{\mathrm{T}} X_{t} .
$$

This equation describes the optimal choice of dividends by firms in the $\mathrm{H}$ traded goods sector given our conjecture about the equilibrium dynamics of the economy. The term in brackets identifies the $\pi_{d}^{\mathrm{T}}$ vector linking log dividends to the state vector.

Before we examine households' decisions, we must derive the implications of firms' dividend choices for the behavior of equity returns. Consider the return on $\mathrm{H}$ traded equity defined in (20). Following Campbell and Shiller (1989), we approximate the log return by

$$
r_{t+1}^{\mathrm{T}}=\rho p_{t+1}^{\mathrm{T}}+(1-\rho) d_{t+1}^{\mathrm{T}}-p_{t}^{\mathrm{T}},
$$

with $\rho \equiv 1 /\left(1+\left(D^{\mathrm{T}} / P^{\mathrm{T}}\right)\right)$. In the non-stochastic steady state $\rho=\beta$. Using (32) and (35) to substitute for equity prices and dividends, and setting $\rho=\beta$, we can write the log excess return on traded equity as

$$
e r_{t+1}^{\mathrm{T}} \equiv r_{t+1}^{\mathrm{T}}-r_{t}=\left(\beta \pi_{p}^{\mathrm{T}}+(1-\beta) \pi_{d}^{\mathrm{T}}\right) X_{t+1}-\left(\pi_{p}^{\mathrm{T}}+\pi_{r}\right) X_{t}=\varphi_{1}^{\mathrm{T}} X_{t+1}+\varphi_{2}^{\mathrm{T}} X_{t}
$$

In the HI equilibrium, $\mathrm{H}$ households can choose between bonds, domestic traded and nontraded equity, and $\mathrm{F}$ traded equity. Let $e r_{t+1}^{\prime} \equiv\left[\begin{array}{lll}r_{t+1}^{\mathrm{T}}-r_{t}, & r_{t+1}^{\mathrm{N}}-r_{t}, & r_{t+1}^{\hat{\mathrm{T}}}-r_{t}\end{array}\right]$ be a vector containing log excess returns on $\mathrm{H}$ traded, $\mathrm{H}$ nontraded and $\mathrm{F}$ traded equity. Following the steps above for $\mathrm{H}$ nontraded and $\mathrm{F}$ traded equity we can write

$$
e r_{t+1}=\varphi_{1} X_{t+1}+\varphi_{2} X_{t}
$$

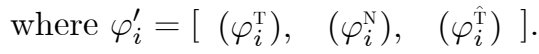

We can now characterize the portfolio and consumption decisions of households. Since preferences are logarithmic, $C_{t}^{\mathrm{T}}+Q_{t}^{\mathrm{N}} C_{t}^{\mathrm{N}}=(1-\beta) W_{t}$. Applying this result to the budget constraint in (7) and taking $\operatorname{logs}$ gives us

$$
\ln \left(W_{t+1} / W_{t}\right) \equiv \Delta w_{t+1}=\ln \beta+r_{t+1}^{\mathrm{W}},
$$

where $r_{t+1}^{\mathrm{W}}$ is the log return on optimally invested wealth defined in (8). Campbell, Chan and Viceira (2003) show that this log return is well-approximated by

$$
r_{t+1}^{\mathrm{W}}=r_{t}+\boldsymbol{\alpha}_{t}^{\prime} e r_{t+1}+\frac{1}{2} \boldsymbol{\alpha}_{t}^{\prime}\left(\operatorname{diag}\left(\mathbb{V}_{t}\left(e r_{t+1}\right)\right)-\mathbb{V}_{t}\left(e r_{t+1}\right) \boldsymbol{\alpha}_{t}\right),
$$

where $\boldsymbol{\alpha}_{t}^{\prime} \equiv\left[\begin{array}{lll}\alpha_{t}^{\mathrm{T}}, & \alpha_{t}^{\mathrm{N}}, & \alpha_{t}^{\hat{\mathrm{T}}}\end{array}\right]$ is the vector of portfolio shares. As in the case of the conjectured state dynamics, the approximation error associated with this expression disappears in the limit when shocks to asset prices follow Brownian motion.

The optimal portfolio shares are found by combining (38) and (39) with the a log-normal approximation 
of the first-order conditions in (19a) - (19e):

$$
\begin{aligned}
\mathbb{E}_{t}\left[e r_{t+1}^{\varkappa}\right]+\frac{1}{2} \mathbb{V}_{t}\left(e r_{t+1}^{\varkappa}\right) & =-\mathbb{C V}_{t}\left(m_{t+1}, e r_{t+1}^{\varkappa}\right), \\
r_{t} & =-\mathbb{E}_{t}\left[m_{t+1}\right]-\frac{1}{2} \mathbb{V}_{t}\left(m_{t+1}\right),
\end{aligned}
$$

for $\varkappa=\{\mathrm{T}, \mathrm{N}, \hat{\mathrm{T}}\}$. We noted above that $m_{t+1}=\ln \beta-\Delta w_{t+1}$ with our log specification for preferences, so (40a) can be rewritten in vector form as

$$
\mathbb{E}_{t}\left[e r_{t+1}\right]=\mathbb{V}_{t}\left(e r_{t+1}\right) \boldsymbol{\alpha}_{t}-\frac{1}{2} \operatorname{diag}\left(\mathbb{V}_{t}\left(e r_{t+1}\right)\right)
$$

This equation implicitly identifies the relation between the optimal portfolio shares and the state vector. To see how, we first use the equation for log excess returns in (37) and our conjecture about the state dynamics from Step 1 to write

$\mathbb{E}_{t}\left[e r_{t+1}\right]=\left[\begin{array}{c}\varphi_{1}^{\mathrm{T}} \\ \varphi_{1}^{\mathrm{N}} \\ \varphi_{1}^{\mathrm{T}}\end{array}\right] \mathbb{A} X_{t}+\left[\begin{array}{c}\varphi_{2}^{\mathrm{T}} \\ \varphi_{2}^{\mathrm{N}} \\ \varphi_{2}^{\hat{\mathrm{T}}}\end{array}\right] X_{t}, \quad$ and $\quad \mathbb{V}_{t}\left(e r_{t+1}\right)=\left[\begin{array}{ccc}\mathcal{A}\left(\varphi_{1}^{\mathrm{T}}, \varphi_{1}^{\mathrm{T}}\right) X_{t} & \mathcal{A}\left(\varphi_{1}^{\mathrm{T}}, \varphi_{1}^{\mathrm{N}}\right) X_{t} & \mathcal{A}\left(\varphi_{1}^{\mathrm{T}}, \varphi_{1}^{\hat{\mathrm{T}}}\right) X_{t} \\ \mathcal{A}\left(\varphi_{1}^{\mathrm{N}}, \varphi_{1}^{\mathrm{T}}\right) X_{t} & \mathcal{A}\left(\varphi_{1}^{\mathrm{N}}, \varphi_{1}^{\mathrm{N}}\right) X_{t} & \mathcal{A}\left(\varphi_{1}^{\mathrm{N}}, \varphi_{1}^{\hat{\mathrm{T}}}\right) X_{t} \\ \mathcal{A}\left(\varphi_{1}^{\hat{\mathrm{T}}}, \varphi_{1}^{\mathrm{T}}\right) X_{t} & \mathcal{A}\left(\varphi_{1}^{\mathrm{T}}, \varphi_{1}^{\mathrm{N}}\right) X_{t} & \mathcal{A}\left(\varphi_{1}^{\hat{\mathrm{T}}}, \varphi_{1}^{\hat{\mathrm{T}}}\right) X_{t}\end{array}\right]$

Now let the vector $\pi_{\alpha}^{\varkappa}$ define the linear relation between the period-t share of equity asset $\varkappa$ and the state vector (i.e., $\alpha_{t}^{\varkappa}=\pi_{\alpha}^{\varkappa} X_{t}$ for $\varkappa=\{\mathrm{T}, \mathrm{N}, \hat{\mathrm{T}}\}$ ). Substituting the expressions above for $\mathbb{E}\left[e r_{t+1} \mid X_{t}\right]$ and $\mathbb{V}\left[e r_{t+1} \mid X_{t}\right]$ into (41) and applying the product operator in (31) gives

$$
\left[\varphi_{1}^{\varkappa} \mathbb{A}+\varphi_{2}^{\varkappa}\right] X_{t}=\left[\mathcal{B}\left(\mathcal{A}\left(\varphi_{1}^{\varkappa}, \varphi_{1}^{\mathrm{T}}\right), \pi_{\alpha}^{\mathrm{T}}\right)+\mathcal{B}\left(\mathcal{A}\left(\varphi_{1}^{\varkappa}, \varphi_{1}^{\mathrm{N}}\right), \pi_{\alpha}^{\mathrm{N}}\right)+\mathcal{B}\left(\mathcal{A}\left(\varphi_{1}^{\varkappa}, \varphi_{1}^{\hat{\mathrm{T}}}\right), \pi_{\alpha}^{\hat{\mathrm{T}}}\right)-\frac{1}{2} \mathcal{A}\left(\varphi_{1}^{\varkappa}, \varphi_{1}^{\varkappa}\right)\right] X_{t}
$$

This equation must hold for all three equities and all possible values of $X_{t}$ given our Step 1 conjecture. Hence, the optimal chosen portfolio shares can be represented as

$$
\boldsymbol{\alpha}_{t} \equiv\left[\begin{array}{c}
\alpha_{t}^{\mathrm{T}} \\
\alpha_{t}^{\mathrm{N}} \\
\alpha_{t}^{\mathrm{T}}
\end{array}\right]=\left[\begin{array}{c}
\pi_{\alpha}^{\mathrm{T}} \\
\pi_{\alpha}^{\mathrm{N}} \\
\pi_{\alpha}^{\hat{\mathrm{T}}}
\end{array}\right] X_{t},
$$

where the $\pi_{\alpha}^{\varkappa \prime} s$ satisfy

$$
\varphi_{1}^{\varkappa} \mathbb{A}+\varphi_{2}^{\varkappa}=\mathcal{B}\left(\mathcal{A}\left(\varphi_{1}^{\varkappa}, \varphi_{1}^{\mathrm{T}}\right), \pi_{\alpha}^{\mathrm{T}}\right)+\mathcal{B}\left(\mathcal{A}\left(\varphi_{1}^{\varkappa}, \varphi_{1}^{\mathrm{N}}\right), \pi_{\alpha}^{\mathrm{N}}\right)+\mathcal{B}\left(\mathcal{A}\left(\varphi_{1}^{\varkappa}, \varphi_{1}^{\hat{\mathrm{T}}}\right), \pi_{\alpha}^{\hat{\mathrm{T}}}\right)-\frac{1}{2} \mathcal{A}\left(\varphi_{1}^{\varkappa}, \varphi_{1}^{\varkappa}\right),
$$

for $\varkappa=\{\mathrm{T}, \mathrm{N}, \hat{\mathrm{T}}\}$.

To characterize the optimal consumption of traded and nontraded goods, we combine the first-order condition in (19a) with $C_{t}^{\mathrm{T}}+Q_{t}^{\mathrm{N}} C_{t}^{\mathrm{N}}=(1-\beta) W_{t}$ to obtain $Q_{t}^{\mathrm{N}} C_{t}^{\mathrm{N}}=(1-\beta)\left[1+\eta\left(Q_{t}^{\mathrm{N}}\right)\right]^{-1} W_{t}$ and $C_{t}^{\mathrm{T}}=$ $(1-\beta) \eta\left(Q_{t}^{\mathrm{N}}\right)\left[1+\eta\left(Q_{t}^{\mathrm{N}}\right)\right]^{-1} W_{t}$ where $\eta\left(Q_{t}^{\mathrm{N}}\right) \equiv\left(\lambda_{\mathrm{T}} / \lambda_{\mathrm{N}}\right)\left(Q_{t}^{\mathrm{N}}\right)^{\phi /(1-\phi)}$. Log-linearizing these expressions around 
the initial value of $Q_{t}^{\mathrm{N}}$ gives

$$
\begin{aligned}
c_{t}^{\mathrm{T}} & =\left[c^{\mathrm{T}} \imath_{1}+\imath_{w}+\frac{\phi}{(1+\eta)(1-\phi)}\left(\pi_{q}^{\mathrm{N}}-q^{\mathrm{N}} \imath_{1}\right)\right] X_{t}=\pi_{c}^{\mathrm{T}} X_{t}, \\
c_{t}^{\mathrm{N}} & =\left[c^{\mathrm{N}} \imath_{1}+\imath_{w}-\frac{1-\phi+\eta}{(1+\eta)(1-\phi)}\left(\pi_{q}^{\mathrm{N}}-q^{\mathrm{N}} \imath_{1}\right)\right] X_{t}=\pi_{c}^{\mathrm{N}} X_{t},
\end{aligned}
$$

with $\eta$ denoting the initial value of $\eta\left(Q_{t}^{\mathrm{N}}\right)$. As above, the terms in bracket identify the $\pi$ vectors linking consumption to the state vector.

We have now characterized the optimal choice of dividends, consumption and portfolio shares in country $\mathrm{H}$ given our Step 1 conjecture about the dynamics of the economy. Applying an analogous procedure to decisions of $\mathrm{F}$ firms and households gives us expressions for the $\pi$ vectors that identify dividends, $d_{t}^{\hat{\mathbb{N}}}=\pi_{d}^{\hat{\mathrm{N}}} X_{t}$ and $\hat{d}_{t}^{\mathrm{T}}=\pi_{\hat{d}}^{\mathrm{T}} X_{t}$; consumption, $\hat{c}_{t}^{\hat{\mathrm{N}}}=\pi_{\hat{c}}^{\hat{\mathrm{N}}} X_{t}$ and $\hat{c}_{t}^{\mathrm{T}}=\pi_{\hat{c}}^{\mathrm{T}} X_{t}$; and the portfolio shares $\hat{\alpha}_{t}^{\varkappa}=\pi_{\hat{\alpha}}^{\varkappa} X_{t}$ for $\varkappa=\{\hat{\mathrm{T}}$, $\hat{\mathrm{N}}, \mathrm{T}\}$.

Step 3 We now consider the implications of households' and firms' decisions for the equilibrium behavior of the $\mathrm{H}$ and $\mathrm{F}$ economies. Our task is to identify the parameters of the $x_{t}$ process in (27) and the $\pi$ vectors identifying log prices and the log interest rate consistent with market clearing and the optimal behavior of firms and households derived in Step 2. As above, we focus on the HI equilibrium to illustrate this process.

We begin with the implications of market clearing. In the HI equilibrium, market clearing in the goods markets requires $D_{t}^{\mathrm{N}}=\kappa Z_{t}^{\mathrm{N}}, \hat{D}_{t}^{\mathrm{N}}=\kappa \hat{Z}_{t}^{\mathrm{N}}$ and $D_{t}^{\mathrm{T}}+\hat{D}_{t}^{\mathrm{T}}=C_{t}^{\mathrm{T}}+\hat{C}_{t}^{\mathrm{T}}$. The first two conditions were automatically satisfied in Step 2, so we focus on the traded goods market. Rewriting the market clearing condition as $d_{t}^{\mathrm{T}}+\ln \left(1+\exp \left(\hat{d}_{t}^{\mathrm{T}}-d_{t}^{\mathrm{T}}\right)=c_{t}+\ln \left(1+\exp \left(\hat{c}_{t}^{\mathrm{T}}-c_{t}^{\mathrm{T}}\right)\right)\right.$, taking a second-order approximations on both sides around the initial values for consumption and steady state values for dividends (see below), and equating coefficients using the product operator in (31) gives

$$
\pi_{d}^{\mathrm{T}}+\pi_{\hat{d}}^{\mathrm{T}}+\frac{1}{4} \mathcal{B}\left(\pi_{\hat{d}}^{\mathrm{T}}-\pi_{d}^{\mathrm{T}}, \pi_{\hat{d}}^{\mathrm{T}}-\pi_{d}^{\mathrm{T}}\right)=\pi_{c}^{\mathrm{T}}+\pi_{\hat{c}}^{\mathrm{T}}+\frac{1}{4} \mathcal{B}\left(\pi_{\hat{c}}^{\mathrm{T}}-\pi_{c}^{\mathrm{T}}, \pi_{\hat{c}}^{\mathrm{T}}-\pi_{c}^{\mathrm{T}}\right)
$$

Market clearing in the nontraded equity requires $\alpha_{t}^{\mathrm{N}}=\exp \left(q_{t}^{\mathrm{N}}+p_{t}^{\mathrm{N}}-w_{t}\right) / \beta$ and $\hat{\alpha}_{t}^{\hat{\mathrm{N}}}=\exp \left(q_{t}^{\hat{\mathrm{N}}}+p_{t}^{\hat{\mathrm{N}}}-\hat{w}_{t}\right) / \beta$. Using the same approach we obtain

$$
\pi_{\alpha}^{\mathrm{N}}=\alpha^{\mathrm{N}}\left[\imath_{1}+\pi_{q}^{\mathrm{N}}+\pi_{p}^{\mathrm{N}}-\imath_{w}+\frac{1}{2} \mathcal{B}\left(\pi_{q}^{\mathrm{N}}+\pi_{p}^{\mathrm{N}}-\imath_{w}, \pi_{q}^{\mathrm{N}}+\pi_{p}^{\mathrm{N}}-\imath_{w}\right)\right]
$$

and

$$
\pi_{\hat{\alpha}}^{\hat{\mathrm{N}}}=\hat{\alpha}^{\mathrm{N}}\left[\imath_{1}+\pi_{q}^{\hat{\mathrm{N}}}+\pi_{p}^{\hat{\mathrm{N}}}-\imath_{\hat{w}}+\frac{1}{2} \mathcal{B}\left(\pi_{q}^{\hat{\mathrm{N}}}+\pi_{p}^{\hat{\mathrm{N}}}-\imath_{\hat{w}}, \pi_{q}^{\hat{\mathrm{N}}}+\pi_{p}^{\hat{\mathrm{N}}}-\imath_{\hat{w}}\right)\right],
$$

where $\alpha^{\mathrm{N}}$ and $\hat{\alpha}^{\mathrm{N}}$ are the initial values of $\alpha_{t}^{\mathrm{N}}$ and $\hat{\alpha}_{t}^{\mathrm{N}}$. These values are pinned down by the steady state shares of nontraded consumption in the total consumption expenditure. When tradable and nontradable sectors are of equal size, as in our model, $\alpha^{\mathrm{N}}=\hat{\alpha}^{\mathrm{N}}=1 / 2$.

Market clearing in traded equity requires that $\exp \left(p_{t}^{\mathrm{T}}-w_{t}\right) / \beta=\alpha_{t}^{\mathrm{T}}+\hat{\alpha}_{t}^{\mathrm{T}} \exp \left(\hat{w}_{t}-w_{t}\right)$ and $\exp \left(\hat{p}_{t}^{\mathrm{T}}-\hat{w}_{t}\right) / \beta=$ $\hat{\alpha}_{t}^{\hat{\mathrm{T}}}+\alpha_{t}^{\hat{\mathrm{T}}} \exp \left(w_{t}-\hat{w}_{t}\right)$. Here we approximate the left hand side around the steady state values for $P_{t}^{\mathrm{T}} / W_{t} \beta$ and $\hat{P}_{t}^{\mathrm{T}} / \hat{W}_{t} \beta$ and the right hand side around the initial wealth ratio $\hat{W}_{0} / W_{0}$, which we take to equal one. 
In this particular case, it is straightforward to show that the steady state values of $P_{t}^{\mathrm{T}} / W_{t} \beta$ and $\hat{P}_{t}^{\mathrm{T}} / \hat{W}_{t} \beta$ equal $1 / 2$, so a second-order approximation to both sides of the market clearing conditions give

$$
\alpha^{\mathrm{T}}\left[1+p_{t}^{\mathrm{T}}-w_{t}+\frac{1}{2}\left(p_{t}^{\mathrm{T}}-w_{t}\right)^{2}\right]=\alpha_{t}^{\mathrm{T}}+\hat{\alpha}_{t}^{\mathrm{T}}\left(1+\hat{w}_{t}-w_{t}+\frac{1}{2}\left(\hat{w}_{t}-w_{t}\right)^{2}\right)
$$

and

$$
\alpha^{\hat{\mathrm{T}}}\left[1+\hat{p}_{t}^{\mathrm{T}}-\hat{w}_{t}+\frac{1}{2}\left(\hat{p}_{t}^{\mathrm{T}}-\hat{w}_{t}\right)^{2}\right]=\hat{\alpha}_{t}^{\hat{\mathrm{T}}}+\alpha_{t}^{\hat{\mathrm{T}}}\left(1+w_{t}-\hat{w}_{t}+\frac{1}{2}\left(w_{t}-\hat{w}_{t}\right)^{2}\right),
$$

where $\alpha^{\mathrm{T}}$ is the initial value of $\alpha_{t}^{\mathrm{T}}+\hat{\alpha}_{t}^{\mathrm{T}}$, and $\alpha^{\hat{\mathrm{T}}}$ is the initial value of $\hat{\alpha}_{t}^{\hat{\mathrm{T}}}+\alpha_{t}^{\hat{\mathrm{T}}} ; \alpha^{\mathrm{T}}=\alpha^{\hat{\mathrm{T}}}=1 / 2$. Substituting for $p_{t}^{\mathrm{T}}, \hat{p}_{t}^{\mathrm{T}}, w_{t}, \hat{w}_{t}, \alpha_{t}^{\mathrm{T}}, \hat{\alpha}_{t}^{\mathrm{T}}, \hat{\alpha}_{t}^{\hat{\mathrm{T}}}$ and $\alpha_{t}^{\hat{\mathrm{T}}}$, applying the product operator in (31) and equating coefficients leads to the restrictions:

$$
\alpha^{\mathrm{T}}\left[\imath_{1}+\pi_{p}^{\mathrm{T}}-\imath_{w}+\frac{1}{2} \mathcal{B}\left(\pi_{p}^{\mathrm{T}}-\imath_{w}, \pi_{p}^{\mathrm{T}}-\imath_{w}\right)\right]=\pi_{\alpha}^{\mathrm{T}}+\mathcal{B}\left(\pi_{\hat{\alpha}}^{\mathrm{T}},\left[\imath_{1}+\imath_{\hat{w}}-\imath_{w}+\frac{1}{2} \mathcal{B}\left(\imath_{\hat{w}}-\imath_{w}, \imath_{\hat{w}}-\imath_{w}\right)\right]\right)
$$

and

$$
\alpha^{\hat{\mathrm{T}}}\left[\imath_{1}+\pi_{\hat{p}}^{\mathrm{T}}-\imath_{\hat{w}}+\frac{1}{2} \mathcal{B}\left(\pi_{\hat{p}}^{\mathrm{T}}-\imath_{\hat{w}}, \pi_{\hat{p}}^{\mathrm{T}}-\imath_{\hat{w}}\right)\right]=\pi_{\hat{\alpha}}^{\hat{\hat{T}}}+\mathcal{B}\left(\pi_{\alpha}^{\hat{\mathrm{T}}},\left[\imath_{1}+\imath_{w}-\imath_{\hat{w}}+\frac{1}{2} \mathcal{B}\left(\imath_{w}-\imath_{\hat{w}}, \imath_{w}-\imath_{\hat{w}}\right)\right]\right) .
$$

Finally we turn to the bond market clearing condition: $B_{t}+\hat{B}_{t}=0$. Substituting for bonds from (26) into this condition gives $\beta\left(W_{t}+\hat{W}_{t}\right)=P_{t}^{\mathrm{T}}+P_{t}^{\hat{\mathrm{T}}}+Q_{t}^{\mathrm{N}} P_{t}^{\mathrm{N}}+Q_{t}^{\hat{\mathrm{N}}} P_{t}^{\hat{\mathrm{N}}}$. In addition, since aggregate consumption expenditure is a constant fraction of wealth, $(1-\beta)\left(W_{t}+\hat{W}_{t}\right)=C_{t}^{\mathrm{T}}+\hat{C}_{t}^{\mathrm{T}}+Q_{t}^{\mathrm{N}} C_{t}^{\mathrm{N}}+Q_{t}^{\hat{\mathrm{N}}} \hat{C}_{t}^{\hat{\mathrm{N}}}$. Combining these expressions gives

$$
\mathcal{G}\left(p_{t}^{\mathrm{T}}, p_{t}^{\hat{\mathrm{N}}}, q_{t}^{\mathrm{N}}+p_{t}^{\mathrm{N}}, q_{t}^{\hat{\mathrm{N}}}+p_{t}^{\hat{\mathrm{N}}}\right)=\ln \frac{\beta}{1-\beta}+\mathcal{G}\left(c_{t}^{\mathrm{T}}, \hat{c}_{t}^{\mathrm{T}}, q_{t}^{\mathrm{N}}+c_{t}^{\mathrm{N}}, q_{t}^{\hat{\mathrm{N}}}+\hat{c}_{t}^{\hat{\mathrm{N}}}\right)
$$

where $\mathcal{G}(a, b, c, d) \equiv \ln (\exp (a)+\exp (b)+\exp (c)+\exp (d))$. We obtain a further set of restrictions on the $\pi$ vector by taking a second-order approximation to each side of this equation, substituting for the endogenous variables and applying the product operator. This is a straightforward but algebraically messy exercise so we will not present the mathematical details.

Next, we turn to the implications of firms' and households' decisions for equilibrium asset prices and the interest rate. Rewriting households first-order condition (40b) in terms of wealth as $r_{t}=-\ln \beta+$ $\mathbb{E}\left[\Delta w_{t+1} \mid X_{t}\right]-\frac{1}{2} \mathbb{V}\left[w_{t+1} \mid X_{t}\right]$, and substituting for the conditional moments using (29) and (30) from Step 1, gives

$$
r_{t}=\left[\imath_{w}(\mathbb{A}-I)-\frac{1}{2} \mathcal{A}\left(\imath_{w}, \imath_{w}\right)-\ln \beta \imath_{1}\right] X_{t}=\pi_{r} X_{t} .
$$

As above the term in bracket identifies the $\pi_{r}$ vector. Combining this expression with (37) gives us the relation between the state vector and the expected return on equity $\varkappa$ :

$$
E\left[r_{t+1}^{\varkappa} \mid X_{t}\right] \equiv E\left[e r_{t+1}^{\varkappa} \mid X_{t}\right]+r_{t}=\left[\varphi_{1}^{\varkappa} \mathbb{A}+\varphi_{2}^{\varkappa}+\pi_{r}\right] X_{t}
$$

for $\varkappa=\{\mathrm{T}, \mathrm{N}, \hat{\mathrm{T}}\}$.

We now follow Campbell and Shiller (1989) in deriving the relation between log equity prices and $X_{t}$. For H equity $\varkappa$, we rewrite $(36)$ as $p_{t}^{\varkappa}=\beta p_{t+1}^{\varkappa}+(1-\beta) d_{t+1}^{\varkappa}-r_{t+1}^{\varkappa}$, iterate forward, take conditional expectations 
and impose the non-bubble restriction, $\lim _{j \rightarrow \infty} \mathbb{E}_{t} \beta^{j} p_{t+j}^{\varkappa}=0$, to obtain

$$
p_{t}^{\varkappa}=\sum_{i=0}^{\infty} \beta^{i}\left\{(1-\beta) \mathbb{E}_{t}\left[d_{t+1+i}^{\varkappa}\right]-\mathbb{E}_{t}\left[r_{t+1+i}^{\varkappa}\right]\right\}
$$

From Steps 1 and 2 we know that $\mathbb{E}_{t}\left[d_{t+1+i}^{\varkappa}\right]=\pi_{d}^{\varkappa} \mathbb{A}^{i+1} X_{t}$ and $\mathbb{E}_{t}\left[r_{t+1+i}^{\varkappa}\right]=\left[\varphi_{1}^{\varkappa} \mathbb{A}+\varphi_{2}^{\varkappa}+\pi_{r}\right] \mathbb{A}^{i} X_{t}$. Using these expressions to substitute for the expectations in the present value equation gives

$$
p_{t}^{\varkappa}=\left[\left((1-\beta) \pi_{d}^{\varkappa} \mathbb{A}-\left[\varphi_{1}^{\varkappa} \mathbb{A}+\varphi_{2}^{\varkappa}+\pi_{r}\right]\right)(I-\rho \mathbb{A})^{-1}\right] X_{t}=\pi_{p}^{\varkappa} X_{t}
$$

for $\varkappa=\{\mathrm{T}, \mathrm{N}\}$. Once again, the term in brackets identifies the $\pi_{p}^{\varkappa}$ vector. Expressions for log prices of $\mathrm{F}$ equities are derived in an analogous manner.

All that now remains is to pin down the dynamics of $x_{t} \equiv\left[z_{t}, k_{t}, \hat{k}_{t}, w_{t}, \hat{w}_{t}\right]$ which we conjectured followed (27) in Step 1. For this purpose we equate the conditional first and second moments of all the elements in $x_{t}$ with the moments implied by the firms' and households' decisions derived in Step 2. Equation (27) implies that the expectation of the $i^{\prime}$ th. element in $x_{t+1}$ conditioned on $X_{t}$ is given by the $i^{\prime}$ th. row of $\left[\begin{array}{lll}\Phi_{0} & I-\Phi_{1} & \Phi_{2}\end{array}\right] X_{t}$, while the conditional covariance between the $i^{\prime}$ th. and $j$ 'th. elements is equal to $\left[\begin{array}{lll}\Omega_{0}^{i, j} & 0 & \Omega_{1}^{j, .} \otimes \Omega_{1}^{i, .}\end{array}\right] X_{t}$. We now compare these expressions with the moments of equilibrium productivity, capital and wealth.

By assumption, the vector of productivities, $z_{t}$, follows the exogenous AR(1) process in (4) so $\mathbb{E}\left[z_{t+1} \mid X_{t}\right]=$ $\left[\begin{array}{lll}0 & a & 0\end{array}\right] X_{t}$ and $\mathbb{V}\left[z_{t+1} \mid X_{t}\right]=\Omega_{e}$. Equating moments gives the following restrictions on $\Phi_{i}$ and $\Omega_{i}$ parameters of the $x_{t}$ process:

$$
\left[\begin{array}{lll}
0 & a & 0
\end{array}\right]^{i, .}=\left[\begin{array}{lll}
\Phi_{0} & I-\Phi_{1} & \Phi_{2}
\end{array}\right]^{i, .} \quad \text { and } \quad\left[\begin{array}{ccc}
\Omega_{e}^{i, j} & 0 & 0
\end{array}\right]=\left[\begin{array}{ccc}
\Omega_{0}^{i, j} & 0 & \Omega_{1}^{j, .} \otimes \Omega_{1}^{i, .}
\end{array}\right],
$$

for $i=\{1,2,3,4\}$ and $j=\{1,2, . .8\}$. Equations (34b) and (35) imply that the $\mathrm{H}$ capital stock follows $k_{t+1}=\frac{1}{\beta} k_{t}+\frac{\psi}{\beta \theta} z_{t}^{\mathrm{T}}-\frac{\varphi}{\theta \beta}\left(\pi_{d}^{\mathrm{T}}-d^{\mathrm{T}} \imath_{1}\right) X_{t}$ so $\mathbb{E}\left[k_{t+1} \mid X_{t}\right]=\left[\frac{1}{\beta} \imath_{k}+\frac{\psi}{\beta \theta} \imath_{z}^{\mathrm{T}}-\frac{\varphi}{\theta \beta}\left(\pi_{d}^{\mathrm{T}}-d^{\mathrm{T}} \imath_{1}\right)\right] X_{t}$ and $\mathbb{C V}\left[k_{t+1}, x_{t+1}^{j, .} \mid X_{t}\right]=0$ for $j=\{1,2, . .8\}$. The moments restrictions on the $x_{t}$ process parameters are therefore

$$
\left[\frac{1}{\beta} \imath_{k}+\frac{\psi}{\beta \theta} \imath_{z}^{\mathrm{T}}-\frac{\varphi}{\theta \beta}\left(\pi_{d}^{\mathrm{T}}-d^{\mathrm{T}} \imath_{1}\right)\right]=\left[\begin{array}{ccc}
\Phi_{0} & I-\Phi_{1} & \Phi_{2}
\end{array}\right]^{5} \quad \text { and } \quad\left[\begin{array}{lll}
0 & 0 & 0
\end{array}\right]=\left[\begin{array}{lll}
\Omega_{0}^{5, j} & 0 & \Omega_{1}^{j, .} \otimes \Omega_{1}^{5, \cdot}
\end{array}\right]
$$

for $j=\{1,2, . .8\}$. The dynamics of the F capital stock imply an analogous set of restrictions.

To identify the moments involving wealth, we combine (38), (39), and (41) with the identity $e r_{t+1} \equiv$ $\mathbb{E}_{t} e r_{t+1}+\left(e r_{t+1}-\mathbb{E}_{t} e r_{t+1}\right)$ to give

$$
\Delta w_{t+1}=\ln \beta+r_{t}+\frac{1}{2} \boldsymbol{\alpha}_{t}^{\prime} \mathbb{V}_{t}\left(e r_{t+1}\right) \boldsymbol{\alpha}_{t}+\boldsymbol{\alpha}_{t}^{\prime}\left(e r_{t+1}-\mathbb{E}_{t}\left[e r_{t+1}\right]\right)
$$

The first three terms on the right identify the expected growth in wealth under an optimal portfolio allocation. Using the expressions for $\mathbb{V}\left[e r_{t+1} \mid X_{t}\right]$ and $\boldsymbol{\alpha}_{t}$ derived in Step 2, together with the product operator in (31), we can write

$$
\frac{1}{2} \boldsymbol{\alpha}_{t}^{\prime} \mathbb{V}_{t}\left(e r_{t+1}\right) \boldsymbol{\alpha}_{t}=\frac{1}{2} \sum_{\varkappa^{\prime}} \mathcal{B}\left(\pi_{\alpha}^{\varkappa^{\prime}}, \sum_{\varkappa} \mathcal{B}\left(\mathcal{A}\left(\varphi_{1}^{\varkappa^{\prime}}, \varphi_{1}^{\varkappa}\right), \pi_{\alpha}^{\varkappa}\right)\right) X_{t}
$$


where the $\varkappa$ and $\varkappa^{\prime}$ indices pick out the three equities $\{\mathrm{T}, \mathrm{N}, \hat{\mathrm{T}}\}$ available to H households in the HI equilibrium. The restriction on the first conditional moment of wealth is therefore

$$
\ln \beta \imath_{1}+\iota_{w}+\pi_{r}+\frac{1}{2} \sum_{\varkappa^{\prime}} \mathcal{B}\left(\pi_{\alpha}^{\varkappa^{\prime}}, \sum_{\varkappa} \mathcal{B}\left(\mathcal{A}\left(\varphi_{1}^{\varkappa^{\prime}}, \varphi_{1}^{\varkappa}\right), \pi_{\alpha}^{\varkappa}\right)\right)=\left[\begin{array}{lll}
\Phi_{0} & I-\Phi_{1} & \Phi_{2}
\end{array}\right]^{7}
$$

Lastly, we consider the implications of (45) for the covariance between $w_{t+1}$ and all the elements of $x_{t+1}$. According to (45), the conditional covariance between $w_{t+1}$ and the $j^{\prime}$ th. element of $x_{t+1} \equiv \imath^{j} X_{t+1}$ is $\sum_{\varkappa} \alpha_{t}^{\varkappa} \mathbb{C V}_{t}\left(e r_{t+1}^{\varkappa}, \imath^{j} X_{t+1}\right)$ for $\varkappa=\{\mathrm{T}, \mathrm{N}, \hat{\mathrm{T}}\}$. After substituting for $e r_{t+1}^{\varkappa}$ and $\alpha_{t}^{\varkappa}$ with (37) and (42), and using (30) and (31), we can rewrite this covariance as $\sum_{\varkappa} \mathcal{B}\left(\pi_{\alpha}^{\varkappa}, \mathcal{A}\left(\varphi_{1}^{\varkappa}, \imath^{j}\right)\right) X_{t}$. Now (27) implies that this

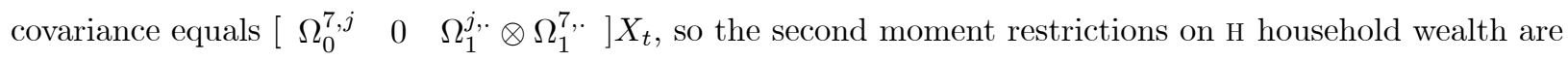

$$
\sum_{\varkappa} \mathcal{B}\left(\pi_{\alpha}^{\varkappa}, \mathcal{A}\left(\varphi_{1}^{\varkappa}, \imath^{j}\right)\right)=\left[\begin{array}{lll}
\Omega_{0}^{7, j} & 0 & \Omega_{1}^{j, .} \otimes \Omega_{1}^{7, \cdot}
\end{array}\right]
$$

for $j=\{1,2, \ldots 8\}$. The dynamics of $\mathrm{F}$ wealth imply a further set of moment restrictions analogous to (46) and (47). These restrictions identify the 8 th rows of $\left[\begin{array}{llll}\Phi_{0} & I-\Phi_{1} & \Phi_{2}\end{array}\right]$ and $\Omega$.

\subsection{The Numerical Algorithm}

To implement the procedure described in the steps above, we need to find the parameters of the $x_{t}$ process $\left\{\Phi_{i}\right.$ and $\left.\Omega_{i}\right\}$, and the $\pi$ vectors that satisfy the restrictions implied by optimality (in Step 2) and market clearing (in Step 3) for a given set of preference and technology parameters. For this purpose we use the following numerical algorithm: First, we choose values for the preference and technology parameters (see below). Next, we make an initial guess for all the unknown elements of the $x_{t}$ process and the $\pi$ vectors for prices in Step 1, $\Xi$. Following Steps 2 and 3 we then derive a new set of $x_{t}$ parameters and $\pi$ vectors consistent with optimality and market clearing. Denote this new set of parameter values by $\Xi^{\prime}$. To "solve" the model we need to find the values of $\Xi$ such that $\Xi=\Xi^{\prime}$. This is done by numerically minimizing the sum of the squared differences between the corresponding elements of $\Xi$ and $\Xi^{\prime}$.

Our solutions to the model use the preference and technology parameter values shown in Table 1. Households' preferences and firms' technologies are assumed symmetric across the two countries, and are calibrated for a period equalling one quarter. We choose $\phi$ so that intratemporal elasticity of substitution between tradables and nontradables at 0.74 , consistent with the value in Corsetti et.al. (2003). The share parameters for traded and nontraded goods, $\lambda_{\mathrm{T}}$ and $\lambda_{\mathrm{N}}$, are both set to 0.5 , and the discount factor $\beta$ is 0.99 . On the technology side, we set the capital share in traded production $\theta$ to 0.36 , and the depreciation rate $\delta$ to 0.02 . These values are consistent with the estimates in Backus et.al. (1995). We assume that each of the four productivity processes (i.e. $\ln Z_{t}^{\mathrm{T}}, \ln \hat{Z}_{t}^{\mathrm{T}}, \ln Z_{t}^{\mathrm{N}}$, and $\ln \hat{Z}_{t}^{\mathrm{N}}$ ) follow independent $\operatorname{AR}(1)$ processes so the $a$ and $\Omega_{e}$ matrices in (4) are both diagonal. The AR(1) coefficients in the processes for traded-goods productivity,

$\ln Z_{t}^{\mathrm{T}}$ and $\ln \hat{Z}_{t}^{\mathrm{T}}$, are 0.78 , while the coefficients for nontraded productivity, $\ln Z_{t}^{\mathrm{N}}$, and $\ln \hat{Z}_{t}^{\mathrm{N}}$, are 0.99 . Shocks to all four productivity process have a variance of 0.0001 . 
Table 1: Model Parameters

\begin{tabular}{ccccc}
\hline \hline & & & & \\
Preferences & $\beta$ & $\lambda_{\mathrm{T}}$ & $\lambda_{\mathrm{N}}$ & $1 /(1-\phi)$ \\
& 0.99 & 0.5 & 0.5 & 0.74 \\
Production & $\theta$ & $\delta$ & & \\
& 0.36 & 0.02 & & \\
Productivity & $a_{i i}^{\mathrm{T}}$ & $a_{i i}^{\mathrm{N}}$ & $\Omega_{e}$ & \\
& 0.78 & 0.99 & 0.0001 & \\
\hline \hline
\end{tabular}

\subsection{Features of the Procedure}

Our solution method has several unique features that are needed to solve models with portfolio choice and incomplete markets. First, we include $\mathrm{H}$ and $\mathrm{F}$ wealth among the set of variables that characterize the state of the economy. Second, we incorporate conditional heteroskedasticity in the conjectured process for the state vector. Third, our method makes no assumption about the stationarity of wealth.

Why do we include $\mathrm{H}$ and $\mathrm{F}$ households' wealth in the state vector $X_{t}$ ? The simple answer is that the distribution of wealth generally affects the behavior of prices in equilibria with incomplete risk-sharing. To illustrate, consider the HI equilibrium in our model. Suppose we tried to find the equilibrium behavior of traded equity prices under the assumption that wealth did not belong in the state vector $X_{t}$. As we noted in Step 3, market clearing in traded equity requires the $\left(P_{t}^{\varkappa} / \beta W_{t}\right)=\alpha_{t}^{\varkappa}+\hat{\alpha}_{t}^{\varkappa}\left(\hat{W}_{t} / W_{t}\right)$ for $\varkappa=\{\mathrm{T}, \hat{\mathrm{T}}\}$ so the relative price of $\mathrm{H}$ and $\mathrm{F}$ traded equity must satisfy

$$
\frac{P_{t}^{\mathrm{T}}}{P_{t}^{\hat{\mathrm{T}}}}=\frac{\alpha_{t}^{\mathrm{T}}+\hat{\alpha}_{t}^{\mathrm{T}}\left(\hat{W}_{t} / W_{t}\right)}{\alpha_{t}^{\hat{\mathrm{T}}}+\hat{\alpha}_{t}^{\hat{\mathrm{T}}}\left(\hat{W}_{t} / W_{t}\right)}
$$

If equilibrium portfolio shares, $\alpha_{t}^{\varkappa}$ and $\hat{\alpha}_{t}^{\varkappa}$, are invariant to variations in the wealth distribution given the state of productivity and the capital stocks, (i.e. the elements of $X_{t}$ ), differentiating this expression with respect to $\hat{W}_{t} / W_{t}$ gives

$$
\left.\frac{d\left(P_{t}^{\mathrm{T}} / P_{t}^{\hat{\mathrm{T}}}\right)}{d\left(\hat{W}_{t} / W_{t}\right)}\right|_{X_{t}}=\frac{\hat{\alpha}_{t}^{\mathrm{T}} \alpha_{t}^{\hat{\mathrm{T}}}-\alpha_{t}^{\mathrm{T}} \hat{\alpha}_{t}^{\hat{\mathrm{T}}}}{\left(\alpha_{t}^{\hat{\mathrm{T}}}+\hat{\alpha}_{t}^{\hat{\mathrm{T}}}\left(\hat{W}_{t} / W_{t}\right)\right)^{2}} .
$$

Recall from equation (41) in Step 2 that the optimal choice of portfolio shares depends on the conditional first and second moments of equity returns. If the behavior of returns is such that $\hat{\alpha}_{t}^{\mathrm{T}} \alpha_{t}^{\hat{\mathrm{T}}} \neq \alpha_{t}^{\mathrm{T}} \hat{\alpha}_{t}^{\hat{\mathrm{T}}}$, the expression above shows that relative equity prices must adjust to changes in the distribution of wealth in order to clear markets. This means that we can leave wealth out of the state vector $X_{t}$ in two situations: First, if markets are complete and preferences are logarithmic, $\hat{W}_{t} / W_{t}$ will be constant so relative equity prices never need to accommodate changes in the wealth distribution. This situation is inapplicable in our model because the array of assets available to households is insufficient for complete risk-sharing. Second, if market are incomplete but the behavior of equilibrium returns is such that $\hat{\alpha}_{t}^{\mathrm{T}} \alpha_{t}^{\hat{\mathrm{T}}}=\alpha_{t}^{\mathrm{T}} \hat{\alpha}_{t}^{\hat{\mathrm{T}}}$, variations in 
$\hat{W}_{t} / W_{t}$ will have no effect on relative equity prices for a given $X_{t}$. This situation may be applicable in our model, but is impossible to check analytically - the model is far too complex to derive analytic expressions for the conditional moments of the equilibrium returns. We therefore need to include wealth in the state vector in recognition of the fact that changes in the distribution of wealth can affect equilibrium prices when markets are incomplete. ${ }^{3}$ Our solution method quantifies the importance of these wealth effects via the values for the elements of the $\pi$ vectors that correspond to wealth in the state vector $X_{t}$.

The presence of wealth in the state vector necessitates the consideration of a conditionally heteroskedastic process for $X_{t}$. To see why, we only need to return to the budget constraint in (7) and the definition of the return on wealth in (8). Combining these equations with the fact that $C_{t}^{\mathrm{T}}+Q_{t}^{\mathrm{N}} C_{t}^{\mathrm{N}}=(1-\beta) W_{t}$ in equilibrium, gives use the following equation for the evolution of wealth

$$
\frac{W_{t+1}}{W_{t}}=\beta E_{t} R_{t+1}^{\mathrm{W}}+\beta\left(\alpha_{t}^{\mathrm{T}}\left(R_{t+1}^{\mathrm{T}}-E_{t} R_{t+1}^{\mathrm{T}}\right)+\alpha_{t}^{\hat{\mathrm{T}}}\left(R_{t+1}^{\hat{\mathrm{T}}}-E_{t} R_{t+1}^{\hat{\mathrm{T}}}\right)+\alpha_{t}^{\mathrm{N}}\left(R_{t+1}^{\mathrm{N}}-E_{t} R_{t+1}^{\hat{\mathrm{T}}}\right)\right) .
$$

The first term on the right identifies the expected growth in wealth. With log preferences this is proportional to the expected return on the household's portfolio, $E_{t} R_{t+1}^{\mathrm{w}}$. The second term identifies the unexpected growth in wealth in terms of the portfolio shares and the unexpected equity returns. Importantly, the susceptibility of wealth in $t+1$ to unexpected returns depends on the period- $t$ portfolio choices, $\boldsymbol{\alpha}_{t}$. Consequently, the volatility of wealth depends endogenously on the portfolio choices made by households and the equilibrium behavior of returns. Our approximation of the budget constraint in (45) retains this key economic feature.

$$
\Delta w_{t+1}=\ln \beta+r_{t}+\frac{1}{2} \boldsymbol{\alpha}_{t}^{\prime} \mathbb{V}_{t}\left(e r_{t+1}\right) \boldsymbol{\alpha}_{t}+\boldsymbol{\alpha}_{t}^{\prime}\left(e r_{t+1}-\mathbb{E}_{t}\left[e r_{t+1}\right]\right) .
$$

Here the susceptibility of $\log$ wealth in period $t+1$ to unexpected log returns depends on period $-t$ portfolio choices via the $\boldsymbol{\alpha}_{t}^{\prime}\left(e r_{t+1}-\mathbb{E}_{t}\left[e r_{t+1}\right]\right)$ term.

In an equilibrium where returns have an i.i.d. distribution, the optimal portfolio shares are constant (see equation (41)) so wealth will be conditionally homoskedastic. Of course in a general equilibrium setting the properties of returns are themselves determined endogenously, so there is no guarantee that optimally chosen portfolio shares or the second moments of returns will be constant. Consequently, when wealth is an element in the state vector, we need to allow for the presence of conditional heteroskedasticity in $X_{t}$. Our solution method reveals the extent to which heteroskedasticity arises in the dynamics of wealth given the optimal choice of $\boldsymbol{\alpha}_{t}$ for a general distribution of equilibrium returns.

The final noteworthy feature of our method concerns the autocorrelation properties of wealth. Our approximation for the dynamics of wealth in (45) does not impose the assumption that log wealth follows a stationary process. Even though the vector of productivities $z_{t}$ follows a stationary process, shocks to productivity may have permanent effects on wealth. Indeed, as we discuss below, there are good economic reasons for shocks to productivity to have permanent effects on equilibrium wealth in some of the equilibria we study. A solution method that assumed stationarity for the dynamics of wealth would therefore be

\footnotetext{
${ }^{3}$ Similar reasoning applies in the LI equilibrium. In particular, bond market clearing requires that $\alpha_{t}^{\mathrm{B}}+\hat{\alpha}_{t}^{\mathrm{B}} \frac{\hat{W}_{t}}{W_{t}}=0$ so the equilibrium interest rate depends on the distribution of wealth. Under FA, all prices are determined by the local market clearing conditions so the distribution of the wealth plays no role. In this case wealth can be excluded from the state vector.
} 
inappropriate. Our procedure allows for permanent wealth effects with one caveat: Our characterization of the equilibrium dynamics are conditioned on a particular initial wealth distribution and are only accurate in a neighborhood of the initial distribution. As a practical matter, this is not a serious limitation because the long-run impact of a productivity shock on log wealth is never large, so typical sample paths for wealth remain in the neighborhood of their initial distributions for many, many periods. When simulating the model we check that the sample paths remain sufficiently close to the initial wealth distribution to ensure that approximation error plays no detectable role in the statistics we study. ${ }^{4}$

\section{Macroeconomic Volatility}

We analyze the implications of financial integration on the volatility of macroeconomic variables in three steps. First, we examine how the economy responds to productivity shocks. Next we compare the volatility and co-movements of consumption and output across the FA, LI, and HI equilibria. Finally, we examine the implications of differing degrees of integration for risk-sharing.

\subsection{The Transmission Mechanism}

The consequences of greater financial integration are most easily understood by considering how the economy responds to productivity shocks. With this in mind, we first examine how positive productivity shocks to domestic firms affect real output and consumption in country H under our three market configurations.

We begin with the case of a positive shock to the productivity of traded firms. Recall that productivity shocks only have temporary affects on the marginal product of capital. Thus, a positive productivity shock in the $\mathrm{H}$ traded-goods sector will induce an immediate rise in real investment as firms in that sector take advantage of the temporarily high marginal product of capital. In short, there is an investment boom in the traded sector of county H. The consequences for traded output, $y_{t}^{\mathrm{T}}$, traded consumption, $c_{t}^{\mathrm{T}}$, and the current account (i.e., the sum of net exports and net foreign income) are shown in the left hand panels of Figure 1.

The upper panel shows that in all three equilibria the investment boom induces an expansion in traded output that lasts for approximately 20 quarters. This pattern closely follows the path of traded productivity, $z_{t}^{\mathrm{T}}$. The middle and lower left hand panels show the responses of traded consumption and the current account in country H. Here there are significant differences in the response patterns across the three equilibria. The initial rise in consumption is highest under FA and lowest under $\mathrm{HI}$, but the persistence of the consumption response is longest under LI. To account for these differences, we first note that the productivity shock raises the equilibrium price of traded equity $P_{t}^{\mathrm{T}}$ because it represents a claim on the stream of future dividends issued by $\mathrm{H}$ traded firms. Under FA and LI, the rise in $P_{t}^{\mathrm{T}}$ represents a capital gain for $\mathrm{H}$ households alone, so the domestic demand for both traded and nontraded goods increase in response to the rise in wealth. Under HI, by contrast, the capital gain is shared between $\mathrm{H}$ and $\mathrm{F}$ households because everyone holds a more diversified portfolio that includes both $\mathrm{H}$ and $\mathrm{F}$ traded equity. As a result, the domestic demand for traded goods rises less under HI than under FA or LI.

\footnotetext{
${ }^{4}$ For a further discussion and formal evaluation of the solution procedure's accuracy, see Evans and Hnatkovska (2006).
} 
T Output, T shock

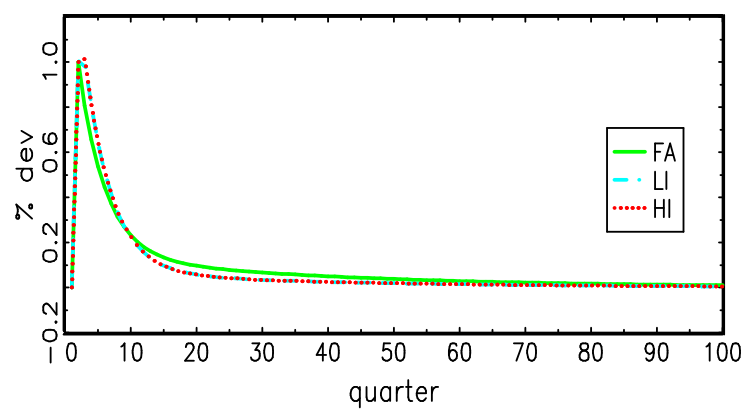

T Consumption, T shock

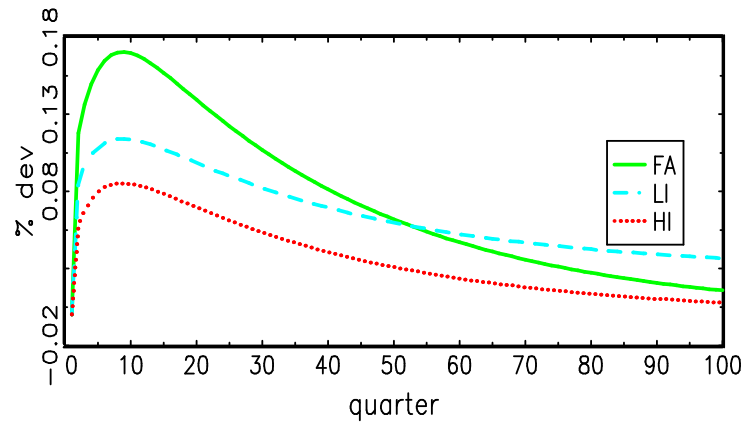

Current Account, T shock

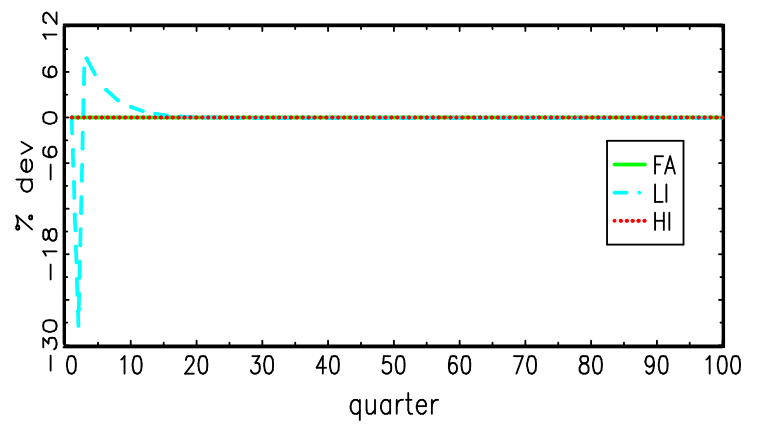

T Output, N shock

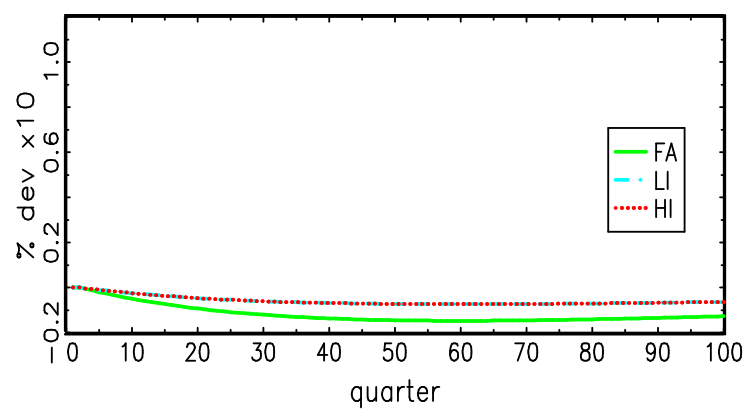

T Consumption, $\mathrm{N}$ shock

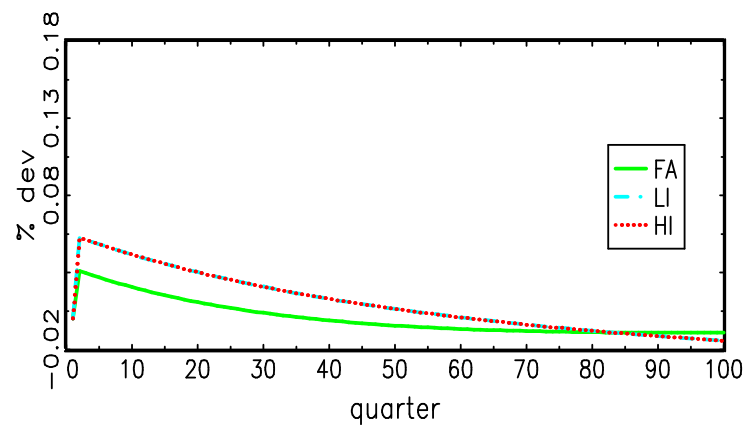

Current Account, $N$ shock

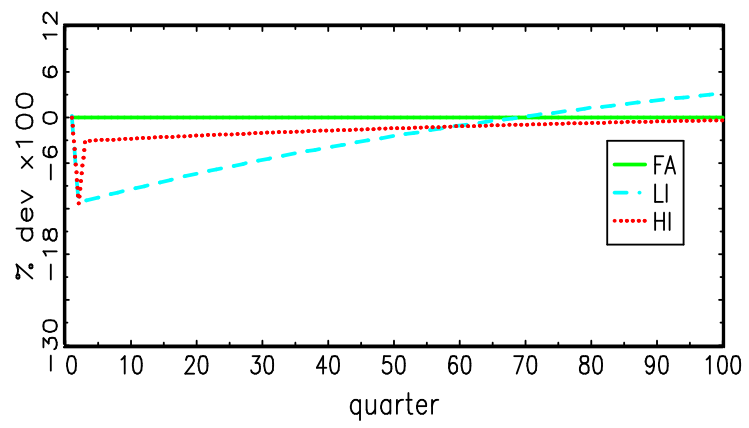

Figure 1: Impulse responses of traded output, traded consumption and the current account for country $\mathrm{H}$ in the FA, LI and HI equilibira. All responses are measured in \% deviations from the value implied by the initial international wealth distribution. The right and left hand columns show the effects of a positive one standard deviation shock to H productivity in the traded and nontraded sectors respectively.

The role played by the international capital markets is depicted in the lower left hand panel of Figure 1. Under LI the increased domestic demand for tradables can be accommodated by both $\mathrm{H}$ and $\mathrm{F}$ firms producing tradables. As a result, the productivity shock is accompanied by an initial current account deficit in the H country as households import traded goods. Once the investment boom is over, the domestic supply of tradables temporarily rises above domestic consumption and country $\mathrm{H}$ runs a trade surplus. Initially, this surplus is used to pay off the foreign debt incurred during the investment boom. Once this is done, 
$\mathrm{H}$ households start lending to $\mathrm{F}$ households by buying bonds. Acting as an international lender enables $\mathrm{H}$ households to permanently raise their consumption of traded goods (see below). The pattern of international borrowing and lending under $\mathrm{HI}$ is different. Here there is a symmetric increase in the demand for traded goods across countries, so prices and interest rates must adjust to insure that the consumption paths of all households are the same. In this case there is no international borrowing or lending so the current account remains in balance and the international distribution of wealth remains unchanged. Consequently, productivity shocks have no permanent affects on the consumption of traded goods.

We can gain further perspective on why the degree of integration affects the persistence of productivity shocks on traded consumption. Our specification for preferences implies that the IMRS for each household is inversely proportional to the growth in wealth (i.e. $M_{t+1}=\beta W_{t} / W_{t+1}$, and $\hat{M}_{t+1}=\beta \hat{W}_{t} / \hat{W}_{t+1}$ ). This means that the first-order conditions impose a cross-country restriction on wealth when financial markets are integrated. In particular, when households have access to the world bond market (i.e. under LI and HI), the expected path of wealth must be the same across countries because everyone faces the same equilibrium interest rate (i.e., the Euler equation for bonds implies $\left.E_{t}\left[W_{t} / W_{t+1}\right]=1 /\left(\beta R_{t}\right)=E_{t}\left[\hat{W}_{t} / \hat{W}_{t+1}\right]\right)$. As a result, if the immediate wealth effects of a productivity shock differ across countries, the difference will be preserved indefinitely in the absence of any future shocks. Thus, if $\mathrm{H}$ wealth rises more than $\mathrm{F}$ wealth in response to a positive $\mathrm{H}$ traded productivity shock (as is the case under LI), $\mathrm{H}$ wealth is expected to remain above F wealth in the future. This can only be achieved in the long run if country H becomes an international lender. The reason is that the demand for traded goods is increasing in wealth, but the expected long-run output of traded goods equals the steady state level in each country. Thus, the international differential in wealth implies a differential in traded consumption that can only be sustained if country $\mathrm{H}$ runs a trade decifit financed by the interest payments it receives as an international lender. By contrast, there is no difference in the wealth effects of traded productivity shocks under HI because households hold diversified equity portfolios. Consequently, the expected path for wealth and traded consumption does not imply the presence of long-run international borrowing or lending.

The right hand panels of Figure 1 show the effects of a positive productivity shock in the H nontraded sector. In the upper panel we see that in all three equilibria traded output falls slightly before gradually returning to its steady state level. (We focus on the behavior of traded rather than nontraded output because the former reflects the endogenous investment decisions of firms.) This pattern occurs because households prefer to consume a balanced basket of traded and nontraded goods. Market clearing insures that the consumption of nontraded goods rises when there is a positive productivity shock in that sector, so households also try to raise their consumption of traded goods. Under FA, an increase in traded consumption can only be accommodated by a fall in investment, so the domestic capital stock falls and output declines. Under LI or HI some of the increased domestic demand for traded goods is met by imports so there is less of a fall in domestic investment with the result that the fall in domestic output is smaller than under FA.

The degree of financial integration also affects the response of traded consumption and the current account. In all three equilibria, traded consumption initially rises. The initial increase is smallest under FA, but eventually consumption returns to its initial value. By contrast, the long-run effect of a positive 
productivity shock in the nontraded sector is to lower traded consumption in the LI and HI equilibria. ${ }^{5}$ As above, these differences in consumption relate to the role played by the international capital markets. Under LI, the initial demand for traded goods is partially met by imports so the $\mathrm{H}$ country runs a current account deficit. Eventually, domestic demand for traded goods falls sufficiently for the trade deficit to turn into a surplus, but the surplus is never large enough for $\mathrm{H}$ households to repay all their international debt. Instead they run a permanent trade surplus to service the outstanding debt and their consumption of traded goods remains below its initial level. Under HI, $\mathrm{H}$ households borrow in the international bond market to finance their initial imports of traded goods and to increase their holdings of $\mathrm{H}$ and $\mathrm{F}$ traded equities. This portfolio shift induces a quick initial fall in the current account deficit, but lengthens its duration. As in the LI case, the trade deficit eventually turns into a permanent surplus sufficient to service the $\mathrm{H}$ household's foreign debt.

Overall, the patterns in Figure 1 show that the behavior of output and consumption in response to productivity shocks varies according to the source of the shock and the degree of financial integration. These differences apply to both the impact of the shocks and their persistence. A productivity shock that has persistent but temporary effects on consumption at one level of financial integration can have permanent effects at another level. In other words, the degree of financial integration affects both the impact and propagation of productivity shocks. Both features are important in understanding how the degree of financial integration affects macroeconomic volatility.

\subsection{Output and Consumption Volatility}

We now consider the implications of financial integration for the volatility of output and consumption. For this purpose, we simulate the model over 400 quarters for each financial configuration \{i.e., FA, PI and FI\}. The innovations to equilibrium wealth are small enough to keep $\mathrm{H}$ and $\mathrm{F}$ wealth close to their initial levels over this span so the approximation errors in the conjectured equilibrium dynamics are very small. The statistics we report below are derived from 100 simulations for each financial configuration and so are based on 10,000 years of simulated quarterly data in the neighborhood of an initial equal distribution of wealth between $\mathrm{H}$ and $\mathrm{F}$ households. We have also examined solutions with unequal initial distributions. The results from simulations based on these solutions are very similar to those presented here. Since some of the variables of interest follow non-stationary time-series process in at least some of the equilibria, all the statistics we report are computed with first-differences of the data. The large size of our simulated data sets ensures that our statistics contain very little sampling error.

Table 2 reports the volatilities and co-movements of consumption and output across the three equilibria. The first three rows compare the volatility of traded consumption growth, $\Delta c_{t}^{\mathrm{T}}$, aggregate consumption growth, $\Delta c_{t}$, and output growth, $\Delta y_{t}$. The volatility of nontraded consumption growth is exogenously determined by nontraded productivity and so is unaffected by the degree of financial integration. The statistics in the first row show that the standard deviation of $\Delta c_{t}^{\mathrm{T}}$ declines by approximately 12 percent between FA and LI, and a further 7 percent between LI and HI. This result is easily understood with the perspective of

\footnotetext{
${ }^{5}$ Admittedly, these long run differences are hard to see in Figure 1 because we only consider a 100 quarter horizon. We present visual evidence of their presence in Figure 2 below.
} 
Table 2. Macroeconomic Volatilities and Correlations

\begin{tabular}{llccc}
\hline \hline & $\begin{array}{c}\text { Autarky, FA } \\
\text { (i) }\end{array}$ & $\begin{array}{c}\text { Low Integration, LI } \\
\text { (ii) }\end{array}$ & $\begin{array}{c}\text { High Integration, HI } \\
\text { (iii) }\end{array}$ \\
\hline & & & & \\
A. Volatilities & $\Delta c_{t}^{\mathrm{T}}$ & 0.1263 & 0.1117 & 0.1039 \\
(\% std. dev.) & $\Delta c_{t}$ & 0.5204 & 0.5300 & 0.5295 \\
& $\Delta y_{t}$ & 0.7858 & 0.8000 & 0.8018 \\
& & & & \\
B. Correlations & $\Delta c_{t}^{\mathrm{T}}, \Delta c_{t}^{\mathrm{N}}$ & 0.2523 & 0.4806 & 0.5153 \\
& $\Delta y_{t}, \Delta c_{t}$ & 0.7653 & 0.7051 & 0.5530 \\
& $m_{t+1}, \hat{m}_{t+1}$ & 0.0000 & 0.5235 & 0.6693 \\
\hline \hline
\end{tabular}

Figure 1. There we saw that greater integration had two effects on the response of traded consumption to productivity shocks. First, shocks to traded productivity had a smaller impact because households could smooth consumption and diversify their asset holdings at higher levels of integration. Second, the desire to consume a smooth balanced basket of traded and nontraded goods induces a greater impact on traded goods consumption from nontraded shocks at higher levels of integration. The volatility of $\Delta c_{t}^{\mathrm{T}}$ declines as integration rises because the first effect dominates.

The volatility of aggregate consumption growth displays a different pattern across the three equilibria. The standard deviation rises by approximately 2 percent between the FA and LI equilibria, and then falls by less than 1 percent between LI and HI. This humped-shaped pattern reflects the changing volatility of traded consumption and its covariation with nontraded consumption. To see this, we use the definition in (6) to approximate aggregate consumption growth as $\Delta c_{t}=\frac{1}{2} \Delta c_{t}^{\mathrm{T}}+\frac{1}{2} \Delta c_{t}^{\mathrm{N}}$. With this expression we can decompose the variance of aggregate consumption growth as

$$
\mathbb{V}\left(\Delta c_{t}\right)=\frac{1}{4} \mathbb{V}\left(\Delta c_{t}^{\mathrm{N}}\right)+\frac{1}{4} \mathbb{V}\left(\Delta c_{t}^{\mathrm{T}}\right)+\frac{1}{2} \mathbb{C} \mathbb{V}\left(\Delta c_{t}^{\mathrm{T}}, \Delta c_{t}^{\mathrm{N}}\right)
$$

where $\mathbb{V}($.$) and \mathbb{C V}(.,$.$) denote the unconditional variance and covariance. The first term on the right$ identifies the contribution of nontraded consumption volatility to the variance of aggregate consumption growth. As note above, $\Delta c_{t}^{\mathrm{N}}$ follows an exogenous process that is invariant to the degree of integration so this term is the same across the three equilibria. The degree of integration does affect the second and third terms. In particular, the volatility of aggregate consumption growth rises as we move from the FA to LI equilibria because the fall in the volatility of traded consumption is dominated by the increase in the covariation between traded and non-traded consumption. The reason is that access to the international bond market allows households to achieve a better balance between their consumption of traded and nontraded goods. As the lower portion of Table 2 shows, the correlation between $\Delta c_{t}^{\mathrm{T}}$ and $\Delta c_{t}^{\mathrm{N}}$ is more than 60 percent higher under LI than FA. As financial integration proceeds further from LI to HI, the volatility of aggregate consumption falls slightly. Here the benefits of greater portfolio diversification allow households to achieve a slightly better consumption balance between traded and nontraded goods, but the resulting rise 
in $\mathbb{C V}\left(\Delta c_{t}^{\mathrm{T}}, \Delta c_{t}^{\mathrm{N}}\right)$ is more than offset by the fall in $\mathbb{V}\left(\Delta c_{t}^{\mathrm{T}}\right) \cdot{ }^{6}$

The third row of Table 2 compares the volatility of output growth across the three equilibria. We compute aggregate output as the aggregate value of output from the traded and nontraded sectors divided by the price index, so the growth in output is computed as $\Delta y_{t} \equiv y_{t}-y_{t-1}$ where $y_{t} \equiv \ln \left[\left(Y_{t}^{\mathrm{T}}+Q_{t}^{\mathrm{N}} Y_{t}^{\mathrm{N}}\right) / Q_{t}\right]$. The statistics in Table 2 show that the volatility of output growth rises slightly with the degree of integration. Since output in the nontraded sector is exogenous, this volatility pattern is a reflection of the similarity in the output of firms in the traded sector across the three equilibria seen in Figure 1.

The remaining statistics in Table 2 report the correlations between aggregate output and consumption growth, and the correlation between the $\log$ IMRS for $\mathrm{H}$ and $\mathrm{F}$ households, $m_{t+1}$ and $\hat{m}_{t+1}$. Under FA, the correlation between output and consumption growth is high but less than one because the dividend policies of firms in the traded goods sector allow households to achieve a modest level of consumption smoothing. Interestingly, this correlation only falls by 8 percent when we move to LI. The marked increase in the correlation between $m_{t+1}$ and $\hat{m}_{t+1}$ shows that access to the international bond market facilitates much more risk-sharing between $\mathrm{H}$ and $\mathrm{F}$ households, but it doesn't significantly weaken the link between aggregate output and consumption growth. As integration proceeds further from LI to HI, there is a further increase in risk sharing as the correlation between $m_{t+1}$ and $\hat{m}_{t+1}$ rises to 0.67 , and a further fall in the output/consumption correlation to 0.55 . These findings illustrate that the correlation between output and consumption is far from a perfect indictor of the degree of risk-sharing. While the output/consumption correlations suggest that most of the risk-sharing gains occur as we move from the LI to HI equilibria (because this is where the correlation falls most), in fact the largest risk-sharing gain occurs between FA and LI.

For further perspective on how financial integration affects macroeconomic volatility, we next examine the components of consumption and output. With log preferences, households' aggregate consumption expenditure, $Q_{t} C_{t} \equiv C_{t}^{\mathrm{T}}+Q_{t}^{\mathrm{N}} C_{t}^{\mathrm{N}}$, is proportional to wealth, $W_{t}$, so aggregate consumption growth is equal to the growth in real wealth: $\Delta c_{t+1}=\Delta w_{t+1}-\Delta q_{t+1}$. Multiplying both sides of this expression by $\Delta c_{t+1}$ and taking expectations gives us the following decomposition for the variance of consumption growth:

$$
\mathbb{V}\left(\Delta c_{t+1}\right)=\mathbb{C V}\left(\Delta w_{t+1}, \Delta c_{t+1}\right)+\mathbb{C V}\left(-\Delta q_{t+1}, \Delta c_{t+1}\right)
$$

The first term on the right identifies the variance contribution of changing wealth, the second identifies the variance contribution of relative price changes (recall that the aggregate price level $Q_{t}$ is a function of $Q_{t}^{N}$ ). We can further decompose the first term by substituting for $\Delta w_{t+1}$ with (45) to give

$$
\begin{aligned}
\mathbb{C V}\left(\Delta w_{t+1}, \Delta c_{t+1}\right)= & \mathbb{C V}\left(r_{t}, \Delta c_{t+1}\right)+\mathbb{C V}\left(\frac{1}{2} \boldsymbol{\alpha}_{t}^{\prime} \mathbb{V}_{t}\left(e r_{t+1}\right) \boldsymbol{\alpha}_{t}, \Delta c_{t+1}\right) \\
& +\mathbb{C V}\left(\boldsymbol{\alpha}_{t}^{\prime}\left(e r_{t+1}-\mathbb{E}_{t}\left[e r_{t+1}\right]\right), \Delta c_{t+1}\right)
\end{aligned}
$$

The first and second terms in this expression identify the contribution of the changing interest rate and expected excess returns to consumption volatility. Since both $r_{t}$ and $\boldsymbol{\alpha}_{t}^{\prime} \mathbb{V}_{t}\left(e r_{t+1}\right) \boldsymbol{\alpha}_{t}$ are known to households

\footnotetext{
${ }^{6}$ Which effect is dominant depends on the curvature of the period sub-utility function and the elasticity of substitution between tradables and nontrables (see Tesar 1993, and Baxter et. al. 1998).
} 
Table 3. Volatility Decomposition for Aggregate Consumption

\begin{tabular}{llccc}
\hline \hline & & $\begin{array}{c}\text { Autarky, FA } \\
\text { (i) }\end{array}$ & $\begin{array}{c}\text { Low Integration, LI } \\
\text { (ii) }\end{array}$ & $\begin{array}{c}\text { High Integration, HI } \\
\text { (iii) }\end{array}$ \\
\hline & & & & \\
$\mathrm{A}$ & $\mathbb{C V}\left(\Delta w_{t+1}, \Delta c_{t+1}\right)$ & -0.2313 & -0.1913 & -0.1955 \\
& $\mathbb{C V}\left(-\Delta q_{t+1}, \Delta c_{t+1}\right)$ & 1.2313 & 1.1913 & 1.1955 \\
& & & \\
$\mathrm{~B}$ & $\mathbb{C V}\left(r_{t}, \Delta c_{t+1}\right)$ & -0.0058 & -0.0032 & -0.0031 \\
& $\mathbb{C V}\left(\frac{1}{2} \boldsymbol{\alpha}_{t}^{\prime} \mathbb{V}\left[e r_{t+1} \mid X_{t}\right] \boldsymbol{\alpha}_{t}, \Delta c_{t+1}\right)$ & 0.0000 & 0.0000 & 0.0000 \\
& $\mathbb{C V}\left(\boldsymbol{\alpha}_{t}^{\prime}\left(e r_{t+1}-\mathbb{E}_{t}\left[e r_{t+1}\right]\right), \Delta c_{t+1}\right)$ & 1.0058 & 1.0032 & 1.0031 \\
& & & \\
\hline \hline
\end{tabular}

at the start of period $t$, these terms represent sources of expected consumption growth volatility. ${ }^{7}$ The third term in (49) identifies the volatility contribution of unexpected equity returns.

Table 3 shows how the components of aggregate consumption volatility vary with the degree of financial integration. Panel A reports the relative contributions of the two covariance terms in (48) to the variance of consumption. These statistics show that consumption growth co-varies negatively with both wealth and prices across the three equilibria. The reason for this is straightforward: Positive productivity shocks raise aggregate consumption because households try to balance their consumption of traded and nontraded goods. When a positive productivity shock hits the traded sector there is a small rise in the relative price of nontraded goods, but when they hit the nontraded sector the relative price falls sharply. As a result, a typical productivity shock raises aggregate consumption but lowers the price level. The statistics show that this relation between consumption and prices is slightly weaker at higher levels of financial integration but still dominates the covariation between consumption and nominal wealth. Panel B of the table examines the factors driving the covariation between wealth and aggregate consumption. In particular, we report the relative contributions of the three covariance terms in (49) to $\mathbb{C V}\left(\Delta w_{t+1}, \Delta c_{t+1}\right)$. In all three equilibria, variations in unexpected equity returns account for almost all the covariation.

Overall, the results in Table 3 show that the sources of aggregate consumption volatility do not vary significantly with the degree of financial integration. Moreover, almost all of the variations in consumption can be attributed to changes in the relative price of nontraded goods and unexpected capital gains on equities.

Table 2 showed that the degree of financial integration had a much larger impact on the volatility of traded consumption than on output. These two observations imply that the behavior of investment and the trade balance differ significantly across the three equilibria. To quantify these differences, we combine the identities $Q_{t} Y_{t} \equiv Y_{t}^{\mathrm{T}}+Q_{t}^{\mathrm{N}} Y_{t}^{\mathrm{N}}$ and $Q_{t} C_{t} \equiv C_{t}^{\mathrm{T}}+Q_{t}^{\mathrm{N}} C_{t}^{\mathrm{N}}$ together with the market clearing condition for nontraded goods to give $Q_{t} Y_{t}-Q_{t} C_{t}=Y_{t}^{\mathrm{T}}-C_{t}^{\mathrm{T}}=I_{t}^{\mathrm{T}}+D_{t}^{\mathrm{T}}-C_{t}^{\mathrm{T}}$. Rearranging this expression and

\footnotetext{
${ }^{7}$ To see this more formally, we use the fact that

$$
\mathbb{C V}\left(\varkappa_{t}, \Delta c_{t+1}\right) \equiv \mathbb{C V}\left(\varkappa_{t}, \mathbb{E}_{t} \Delta c_{t+1}\right)+\mathbb{C V}\left(\varkappa_{t}, \Delta c_{t+1}-\mathbb{E}_{t} \Delta c_{t+1}\right)=\mathbb{C V}\left(\varkappa_{t}, \mathbb{E}_{t} \Delta c_{t+1}\right)
$$
}

for any variable $\varkappa_{t}$ in the period $-t$ information set. We can therefore rewrite the first and second terms as $\mathbb{C V}\left(r_{t}, \mathbb{E}_{t} \Delta c_{t+1}\right)+$ $\frac{1}{2} \mathbb{C V}\left(\boldsymbol{\alpha}_{t}^{\prime} \mathbb{V}_{t}\left[e r_{t+1}\right] \boldsymbol{\alpha}_{t}, \mathbb{E}_{t} \Delta c_{t+1}\right)$. 
log-linearizing gives us

$$
\left.\Delta y_{t+1}=\varphi_{\mathrm{C}} \Delta c_{t+1}+\varphi_{\mathrm{I}} \Delta \ln \left(I_{t+1} / Q_{t+1}\right)+\left(1-\varphi_{\mathrm{C}}-\varphi_{\mathrm{I}}\right)\left(\Delta d_{t+1}^{\mathrm{T}}-\Delta c_{t+1}^{\mathrm{T}}\right)\right]
$$

where $\varphi_{\mathrm{C}}$ and $\varphi_{\mathrm{I}}$ are the consumption and investment to output ratios. Aggregate output growth is thus a weighted average of aggregate consumption growth, the growth in real investment, and the growth in real "net exports". ${ }^{8}$ As above, to derive the variance decomposition from this expression we multiply both sides by $\Delta y_{t+1}$ and take expectations:

$$
\begin{aligned}
\mathbb{V}\left(\Delta y_{t+1}\right)= & \varphi_{\mathrm{C}} \mathbb{C V}\left(\Delta c_{t+1}, \Delta y_{t+1}\right)+\varphi_{\mathrm{I}} \mathbb{C V}\left(\Delta \ln \left(I_{t+1} / Q_{t+1}\right), \Delta y_{t+1}\right) \\
& +\left(1-\varphi_{\mathrm{C}}-\varphi_{\mathrm{I}}\right) \mathbb{C V}\left(\Delta d_{t+1}^{\mathrm{T}}-\Delta c_{t+1}^{\mathrm{T}}, \Delta y_{t+1}\right) .
\end{aligned}
$$

Table 4 reports the contribution of the components on the right hand side of (50) across the three equilibria. The statistics in column (i) show that consumption accounts for approximately 42 percent of the volatility of output growth under FA, with the residual 58 percent coming from real investment and trade balance. This pattern changes slightly once households gain access to the international capital markets. The contribution of consumption falls by 4 percent under LI and by a further 3 percent under HI. From this perspective, greater integration facilitates a modest increase in consumption smoothing. There is a greater change in the behavior of investment and "net exports". As we noted above, positive productivity shocks in the traded sector induce investment booms as firms take advantage of the temporary rise in the marginal product of capital. Under FA, these booms are tempered because firms try to provide a smooth flow of dividends to their shareholders. However, once households gain access to the international capital markets, they are better able to smooth consumption in the face of dividend variations, so firms have a stronger incentive to take advantage of fluctuations in the marginal product of capital. Consequently, investment becomes very volatile and pro-cyclical while net exports become strongly counter-cyclical. According to the statistics in Table 4, one percent higher growth in output under LI is typically associated with 2.9 percent growth in real investment and 2.3 percent fall in "net exports". The pattern under HI is very similar. Giving households greater access to international capital markets does not materially affect the behavior of real investment.

\subsection{Sources of Risk-Sharing}

In Table 2 we showed that greater financial integration allows for increased risk-sharing between $\mathrm{H}$ and $\mathrm{F}$ households. In particular, when households gain access to the international bond market, the correlation between the $\log$ IMRS for $\mathrm{H}$ and $\mathrm{F}$ households, $\rho\left(m r s_{t+1}, \widehat{m r s}_{t+1}\right)$, increases from zero to 0.52 . And, when households are able to access foreign traded equity in addition to international bonds, the correlation rises to 0.67. Thus, greater financial integration in our model facilitates greater risk-sharing, but it does not permit complete risk-sharing. We now consider these risk-sharing implications of integration in greater detail. In

\footnotetext{
${ }^{8}$ Strictly speeking, the last term identfies the growth in one plus the ratio of net exports to domestic traded consumption, i.e., $\Delta d_{t+1}^{\mathrm{T}}-\Delta c_{t+1}^{\mathrm{T}}=\Delta \ln \left(1+\left(D_{t+1}^{\mathrm{T}}-C_{t+1}^{\mathrm{T}}\right) / C_{t+1}^{\mathrm{T}}\right)$.
} 
Table 4. Volatility Decomposition for Aggregate Output

\begin{tabular}{lccc}
\hline \hline & $\begin{array}{c}\text { Autarky, FA } \\
\text { (i) }\end{array}$ & $\begin{array}{c}\text { Low Integration, LI } \\
\text { (ii) }\end{array}$ & $\begin{array}{c}\text { High Integration, HI } \\
\text { (iii) }\end{array}$ \\
\hline & & & \\
$\mathbb{C V}\left(\Delta c_{t+1}, \Delta y_{t+1}\right)$ & 0.4222 & 0.4038 & 0.3909 \\
$\mathbb{C V}\left(\Delta \ln \left(I_{t+1} / Q_{t+1}\right), \Delta y_{t+1}\right)$ & 0.5778 & 2.8676 & 2.8902 \\
$\mathbb{C V}\left(\Delta d_{t+1}^{\mathrm{T}}-\Delta c_{t+1}^{\mathrm{T}}\left[-\Delta q_{t+1}\right], \Delta y_{t+1}\right)$ & 0.0000 & -2.2713 & -2.2812 \\
& & & \\
\hline \hline
\end{tabular}

particular, we examine how changing the array of financial assets available to households affects the degree of risk-sharing.

We start from the fact that the IMRS is proportional to the growth in wealth in our model. It follows that

$$
\begin{aligned}
m r s_{t+1} & =\mathbb{E}_{t}\left[r_{t+1}^{w}\right]+\boldsymbol{\alpha}_{t}^{\prime}\left(e r_{t+1}-\mathbb{E}_{t} e r_{t+1}\right) \\
& =r_{t}+\frac{1}{2} \boldsymbol{\alpha}_{t}^{\prime} \mathbb{V}_{t}\left(e r_{t+1}\right) \boldsymbol{\alpha}_{t}+\boldsymbol{\alpha}_{t}^{\prime}\left(e r_{t+1}-\mathbb{E}_{t}\left[e r_{t+1}\right]\right), \\
\widehat{m r s}_{t+1} & =\mathbb{E}_{t}\left[\hat{r}_{t+1}^{w}\right]+\hat{\boldsymbol{\alpha}}_{t}^{\prime}\left(\widehat{e r}_{t+1}-\mathbb{E}_{t}\left[\widehat{e r}_{t+1}\right]\right) \\
& =r_{t}+\frac{1}{2} \hat{\boldsymbol{\alpha}}_{t}^{\prime} \mathbb{V}_{t}\left(\widehat{e r}_{t+1}\right) \hat{\boldsymbol{\alpha}}_{t}+\hat{\boldsymbol{\alpha}}_{t}^{\prime}\left(\widehat{e r}_{t+1}-\mathbb{E}_{t}\left[\widehat{e r}_{t+1}\right]\right) .
\end{aligned}
$$

The first line in (51a) and (51b) writes the log IMRS as the sum of the expected log return on optimally invested wealth, $\mathbb{E}_{t}\left[r_{t+1}^{w}\right]$ and $\mathbb{E}_{t}\left[\hat{r}_{t+1}^{w}\right]$, and unexpected log returns. The latter comprise a weighted average of unexpected $\log$ equity returns with weights given by the portfolio shares, (i.e., the elements of $\boldsymbol{\alpha}_{t}$ and $\hat{\boldsymbol{\alpha}}_{t}$ ). The second line rewrites expected portfolio returns in the LI and HI equilibria as the sum of the risk free rate, $r_{t}$, and expected log excess returns; $\mathbb{E}_{t}\left[e r_{t+1}^{w}\right] \equiv \mathbb{E}_{t}\left[r_{t+1}^{w}-r_{t}\right]=\frac{1}{2} \boldsymbol{\alpha}_{t}^{\prime} \mathbb{V}_{t}\left(e r_{t+1}\right) \boldsymbol{\alpha}_{t}$ for $\mathrm{H}$ households and $\mathbb{E}_{t}\left[\widehat{e r}_{t+1}^{w}\right] \equiv \mathbb{E}_{t}\left[\hat{r}_{t+1}^{w}-r_{t}\right]=\frac{1}{2} \hat{\boldsymbol{\alpha}}_{t}^{\prime} \mathbb{V}_{t}\left(\widehat{e r}_{t+1}\right) \hat{\boldsymbol{\alpha}}_{t}$ for F households.

Equation (51) allows us to identify three sets of factor affecting the degree of risk sharing: (i) correlations between the unexpected excess returns on equities, (ii) variations in the risk free rate, and (iii) the choice of portfolio shares. To quantify the contribution of these factors, we use (51) to write the covariance between the log IMRS' as

$$
\begin{aligned}
\mathbb{C V}\left(m r s_{t+1}, \widehat{m r} s_{t+1}\right)= & \mathbb{E}\left[\boldsymbol{\alpha}_{t}^{\prime} \mathbb{C} \mathbb{V}_{t}\left(e r_{t+1}, \widehat{e r}_{t+1}^{\prime}\right) \hat{\boldsymbol{\alpha}}_{t}\right]+\mathbb{V}\left(r_{t}\right)+\mathbb{C V}\left(\mathbb{E}_{t}\left[e r_{t+1}^{w}\right], \mathbb{E}_{t}\left[\widehat{e r}_{t+1}^{w}\right]\right) \\
& +\mathbb{C V}\left(r_{t}, \mathbb{E}_{t}\left[\widehat{e r}_{t+1}^{w}\right]\right)+\mathbb{C V}\left(r_{t}, \mathbb{E}_{t}\left[e r_{t+1}^{w}\right]\right)
\end{aligned}
$$

The first term on the right identifies the risk-sharing contribution from unexpected equity returns. Recall that $e r_{t+1}$ and $\widehat{e r}_{t+1}$ are the vectors of log excess returns on the array of equities available to $\mathrm{H}$ and $\mathrm{F}$ households. Under FA, households can only hold domestic equities. In this equilibrium returns are uncorrelated across countries so $\mathbb{C V}_{t}\left(e r_{t+1}, \widehat{e r}{ }_{t+1}^{\prime}\right)$ is a $2 \times 2$ null matrix. Under LI, households have access to the same array of 
equities so the elements in $e r_{t+1}$ and $\widehat{e r}_{t+1}$ are unchanged. However, the returns on capital in the traded sectors are now linked via international trade. This means that the returns on $\mathrm{H}$ and $\mathrm{F}$ traded equity are correlated so unexpected equity returns contribute to risk-sharing. Under HI, households have access to all traded equity, so the $e r_{t+1}$ and $\widehat{e r}_{t+1}$ vectors have two common elements. Unexpected returns on equities should contribute more to risk-sharing in this case. The remaining terms in (52) identify the risk-sharing contribution of the expected return on wealth. This comprises the volatility of the risk free rate, and the covariances between expected excess returns across counties and with the risk-free rate. Notice that only the variance term, $\mathbb{V}\left(r_{t}\right)$, would be present if households only had access to an internationally traded risk free bond.

Table 5 reports decompositions for the correlation between the H and F IMRS' based on (52) in the LI and HI equilibria. The first row shows the correlations from Table 2 while the remainder report the contributions of the terms in (52) (i.e., each term is multiplied by $\left.\left(\mathbb{V}\left(m r s_{t+1}\right) \mathbb{V}\left(\widehat{m r} s_{t+1}\right)\right)^{-1 / 2}\right)$. In both the LI and HI equilibria, approximately 96 percent of the correlation in the IMRS comes from the unexpected equity return component. Variations in the risk free rate account for between 3 and 4 percent, while the rest of the terms make an insignificant contribution.

\begin{tabular}{lcc}
\hline \hline \multicolumn{3}{c}{ Table 5. Risk-Sharing Decomposition } \\
\hline \hline & Low Integration, LI & $\begin{array}{c}\text { High Integration, HI } \\
\text { (ii) }\end{array}$ \\
\hline & & \\
$\rho\left(m r s_{t+1}, \widehat{m r s}_{t+1}\right)$ & 0.5235 & 0.6693 \\
$\mathbb{E}\left[\boldsymbol{\alpha}_{t}^{\prime} \mathbb{C V}_{t}\left(e r_{t+1}, \widehat{e r}_{t+1}\right) \hat{\boldsymbol{\alpha}}_{t}\right]$ & 0.5192 & 0.6484 \\
$\mathbb{V}\left(r_{t}\right)$ & 0.0274 & 0.0299 \\
$\mathbb{C V}\left(\mathbb{E}_{t}\left[e r_{t+1}^{w}\right], \mathbb{E}_{t}\left[e \hat{r}_{t+1}^{w}\right]\right)$ & 0.0000 & 0.0000 \\
$\mathbb{C V}\left(r_{t}, \mathbb{E}_{t}\left[e \hat{r}_{t+1}^{w}\right]\right)$ & -0.0110 & -0.0040 \\
$\mathbb{C V}\left(r_{t}, \mathbb{E}_{t}\left[e r_{t+1}^{w}\right]\right)$ & -0.0120 & -0.0059 \\
& & \\
\hline \hline
\end{tabular}

Two features of the results in Table 5 are particularly noteworthy. First, equities contribute most to risk-sharing in the LI equilibrium even though households are excluded from foreign equity markets. The reason is that the structure of equity returns changes when households are given access to the international bond market. For example, a positive shock to nontraded productivity in country H induces higher demand for traded goods by $\mathrm{H}$ households that is filled by domestic output and imports. As a consequence, both $\mathrm{H}$ and $\mathrm{F}$ traded firms are expected to pay lower dividends in the future so the prices of both $\mathrm{H}$ and $\mathrm{F}$ traded equity fall. In short, shocks to nontraded productivity induce a positive correlation in the unexpected returns on traded equity. Shocks to traded productivity have the opposite effect. In this case, a positive shock in country $\mathrm{H}$ leads to a jump appreciation in the price of $\mathrm{H}$ traded equity and a jump depreciation in the price of $\mathrm{F}$ traded equity because the increase in demand for $\mathrm{F}$ traded goods lowers expected future dividends. In our model, the effects of nontraded shocks dominate so traded equity returns are positively correlated in the LI equilibrium and households can share international risk via their domestic equity portfolios. 
The second noteworthy feature of Table 5 concerns the increase in risk-sharing between the LI and HI equilibria. Recall that households gain access to foreign traded equities in the HI equilibrium. Table 5 shows that almost all the increase in risk-sharing is attributable to the diversification of equity portfolios. However, the size of the gain is rather modest. It is only the prohibition on holding foreign nontraded equity that stops complete risk-sharing in this model, yet this restriction keeps $\rho\left(m r s_{t+1}, \widehat{m r}_{t+1}\right)$ well below unity.

We can investigate why equity diversification doesn't facilitate much greater risk-sharing by considering how portfolio choices and the structure of returns contribute to $\mathbb{E}\left[\boldsymbol{\alpha}_{t}^{\prime} \mathbb{C} \mathbb{V}_{t}\left(e r_{t+1}, \widehat{e r}_{t+1}^{\prime}\right) \hat{\boldsymbol{\alpha}}_{t}\right]$. Specifically, let $\boldsymbol{\alpha}_{t}^{\varkappa}$, $\hat{\boldsymbol{\alpha}}_{t}^{\varkappa}, e r_{t+1}^{\varkappa}$ and $\widehat{e r}_{t+1}^{\varkappa}$ denote the vectors of portfolio shares and log excess returns in equilibrium $\varkappa=\{\mathrm{LI}, \mathrm{HI}\}$. We can now write the equity contribution to risk-sharing under HI as

$$
\begin{aligned}
\mathbb{E}\left[\left(\boldsymbol{\alpha}_{t}^{\mathrm{HI}}\right)^{\prime} \mathbb{C} \mathbb{V}_{t}\left(e r_{t+1}^{\mathrm{HI}}, \widehat{e r}_{t+1}^{\mathrm{HI}}\right) \hat{\boldsymbol{\alpha}}_{t}^{\mathrm{HI}}\right]= & \mathbb{E}\left[\left(\boldsymbol{\alpha}_{t}^{*}\right)^{\prime} \mathbb{C V}_{t}\left(e r_{t+1}^{\mathrm{LI}}, \widehat{e r}_{t+1}^{\mathrm{LI}}\right) \hat{\boldsymbol{\alpha}}_{t}^{*}\right] \\
& +\mathbb{E}\left[\left(\boldsymbol{\alpha}_{t}^{\mathrm{HI}}\right)^{\prime} \mathbb{C} \mathbb{V}_{t}\left(e r_{t+1}^{\mathrm{HI}}, \widehat{e r}_{t+1}^{\mathrm{HI} \prime}\right) \hat{\boldsymbol{\alpha}}_{t}^{\mathrm{HI}}-\left(\boldsymbol{\alpha}_{t}^{*}\right)^{\prime} \mathbb{C V}_{t}\left(e r_{t+1}^{\mathrm{LI}}, \widehat{e r}_{t+1}^{\mathrm{LI} \prime}\right) \hat{\boldsymbol{\alpha}}_{t}^{*}\right]
\end{aligned}
$$

The vectors $e r_{t+1}^{\mathrm{LI}}$ and $\widehat{e r}_{t+1}^{\mathrm{LI}}$ contain the log excess returns on domestic nontraded equity and both $\mathrm{H}$ and F traded equity computed from the LI equilibrium. We use the moments of these excess returns together with equation (41) to compute optimal portfolio share vectors, $\boldsymbol{\alpha}_{t}^{*}$ and $\hat{\boldsymbol{\alpha}}_{t}^{*}$. Thus, the first term on the right identifies the contribution if households could diversify their equity holdings by adding foreign traded equity and equity returns continued to behave as in LI equilibrium. The term in the second row of (53) identifies the effect of the changing behavior of returns as we move from the LI to the HI equilibria.

To quantify the risk-sharing implications of equity diversification, we use our model simulations to compute the terms in (53) and multiply the results by $\left(\mathbb{V}\left(m r s_{t+1}\right) \mathbb{V}\left(\widehat{m r} s_{t+1}\right)\right)^{-1 / 2}$ computed from the HI equilibrium. These calculations reveal that diversification contributes approximately 50 percent more to risk-sharing in partial equilibrium than in general equilibrium. Specifically, we calculate that the first term on the RHS of (53) is equal to 0.8979 , and the second is equal to -0.2495 . These results imply that the correlation

$\rho\left(m r s_{t+1}, \widehat{m r} s_{t+1}\right)$ would have risen 38 percent higher (i.e. to 0.9278) as a result of the increased diversification allowed under HI if the behavior of returns had remained unchanged. From this partial equilibrium perspective, the risk-sharing benefits of international portfolio diversification are significant. They are not realized in general equilibrium because equity returns are more strongly correlated across countries under HI than under LI. When households hold more internationally diversified portfolios, the wealth effects of productivity shocks are more dispersed internationally. This dampens the response of equity prices in the sector receiving the shock, and amplifies the response of equity prices in other sectors creating a stronger correlation between unexpected returns. As a result, the gains from equity diversification in the HI equilibrium are less than they appeared ex ante in the LI equilibrium.

\section{Welfare}

This section considers the welfare implications of increased financial integration. First, we compare the welfare of the world population across the three equilibria. Second, we examine how the welfare of individual households change in response to shocks. 
The welfare of each household is easily calculated from the solution of the model. For example, the period $-t$ expected discounted lifetime utility of a country $\mathrm{H}$ household can be written as

$$
\mathbb{U}_{t}=\frac{1}{1-\beta} c_{t}+\frac{1}{1-\beta} \sum_{i=1}^{\infty} \beta^{i} \mathbb{E}_{t}\left[\Delta c_{t+1}\right]
$$

Both terms on the right-hand-side are easily computed from the equilibrium dynamics of aggregate consumption. Our analysis below examines the unconditional welfare of the world population computed as $\mathbb{E}\left[\mathcal{U}_{t}\right]$ where $\mathcal{U}_{t} \equiv \frac{1}{2} \mathbb{U}_{t}+\frac{1}{2} \widehat{\mathbb{U}}_{t}$ and $\widehat{\mathbb{U}}_{t}$ is the period- $t$ welfare of $\mathrm{F}$ country households identified by the "foreign version" of (54).

Table 6 reports the welfare gain in moving from FA to LI in column (i) and from FA to HI in column (ii). Row A shows that the percentage gains in unconditional world welfare are extremely small. Row B presents the gains in terms of "certainty equivalent consumption". This is the constant level of period- $t$ consumption, $\mathcal{C}$, implied by the value of $\mathbb{E}\left[\mathcal{U}_{t}\right]$. With our specification for preferences, $\mathcal{C}=\exp \left\{(1-\beta) \mathbb{E}\left[\mathcal{U}_{t}\right]\right\}$. The statistics in row B indicate that the welfare gain between the FA and HI equilibria is equivalent to less than a 0.01 percent permanent increase in aggregate consumption - an economically insignificant amount. The gain between the FA and LI equilibria is even less.

\begin{tabular}{lcc}
\hline \hline \multicolumn{3}{c}{ Table 6. Welfare Gains } \\
\hline \hline & Low Integration, LI & High Integration, HI \\
& (i) & $($ ii) \\
\hline & & $0.0037 \%$ \\
A: $\mathbb{E}\left[\mathcal{U}_{t}\right]$ & $0.0002 \%$ & $0.0067 \%$ \\
B: $\mathcal{C}_{t}$ & $0.0003 \%$ & \\
\hline \hline
\end{tabular}

Why are the unconditional welfare gains associated with greater financial integration so small? Equation (54) shows that the welfare of $\mathrm{H}$ households depends on current consumption and the present value of consumption growth. Since consumption growth is somewhat predictable, the present value term will contribute to individual household utility in some periods. However, when we average across households and take unconditional expectations in order to compute unconditional world welfare (i.e., $\mathbb{E}\left[\mathcal{U}_{t}\right] \equiv \frac{1}{2} \mathbb{E}\left[\mathbb{U}_{t}\right]+\frac{1}{2} \mathbb{E}\left[\widehat{\mathbb{U}}_{t}\right]$ ), the absence of long run growth in the model means that the present value terms contribute nothing to the value of $\mathbb{E}\left[\mathcal{U}_{t}\right]$. Consequently, an increase in financial integration primarily affects unconditional world welfare via its impact on the average level of aggregate consumption in the two countries. In Table 4 we saw that the fluctuations in real investment contributed much more to the volatility of output under LI and HI than under FA because firms in the traded sector were better able to take advantage of productivity shocks without harming their shareholders. This leads to an efficiency gain in traded production because firms can direct more output towards investment during periods where the marginal product of capital is highest. As a result, average aggregate consumption rises, but only by a very small amount.

These results contrast with the implications of greater financial integration for risk-sharing. Remember 
that the correlation between the log IMRS' rises from zero under FA to 0.52 under LI and to 0.67 under HI, so increased financial integration does facilitate significantly more risk-sharing between households. However, greater risk-sharing has a negligible effect on unconditional welfare in our model because it has no impact on long-run growth. This is not to say that financial integration is irrelevant from a welfare point of view. Indeed, as we shall now show, the degree of financial integration has significant welfare implications for individual households.

Figure 2 examines the implications of differing degrees of financial integration for the welfare of $\mathrm{H}$ and $\mathrm{F}$ households. In Section 5 we saw that productivity shocks can permanently affect the consumption of traded goods in some equilibria because they affect the international distribution of the wealth. As a consequence, while average aggregate consumption across the world is stationary, aggregate consumption within each country is not. For this reason we cannot compare the unconditional welfare for individual households across the three equilibria. Instead, Figure 2 shows how the welfare of $\mathrm{H}$ and $\mathrm{F}$ households, $\mathbb{U}_{t}$ and $\widehat{\mathbb{U}}_{t}$, respond to productivity shocks across the FA, LI and HI equilibria. As above, we translate $\mathbb{U}_{t}$ and $\widehat{\mathbb{U}}_{t}$ into "certainty equivalent consumption", and represent the impact of productivity shocks in terms of percent deviations from the level of "certainty equivalent consumption" implied by the initial equal wealth distribution.

The upper panel of Figure 2 shows the welfare responses to positive productivity shocks in the traded and nontraded sectors of country H under FA. As one would expect, F households are completely insulated from the effects of either shock, so there is no impact on their welfare. Of course, $\mathrm{H}$ households benefit, but the welfare gain disappears as the impact of the shock on productivity dissipates. Notice, also, that the immediate welfare benefits of nontraded productivity shocks are an order of magnitude higher than for traded productivity shocks, and both are much larger than the gains in the unconditional certainty equivalent consumption reported in Table 6.

The middle panel of Figure 2 shows the welfare effects of the same productivity shocks in the LI equilibria. Two features stand out: (i) F households are no longer insulated from the H productivity shocks and (ii) shocks permanently affect welfare. In Section 5 we explained that a positive stock to H traded productivity leads $\mathrm{H}$ households to become international lenders in the long run and enables them to retain a higher level of consumption indefinitely. As a consequence, the welfare of $\mathrm{H}$ households permanently rises, and welfare of $\mathrm{F}$ households permanently falls. In the case of nontraded productivity shocks, $\mathrm{H}$ households become international borrowers in the long run because they never cut back on their consumption of traded goods sufficiently to pay for the initial surge in imports. Consequently, F households act as international lenders so their welfare gradually rises, while the welfare of $\mathrm{H}$ households eventually falls below its initial level. 
FA, T shock

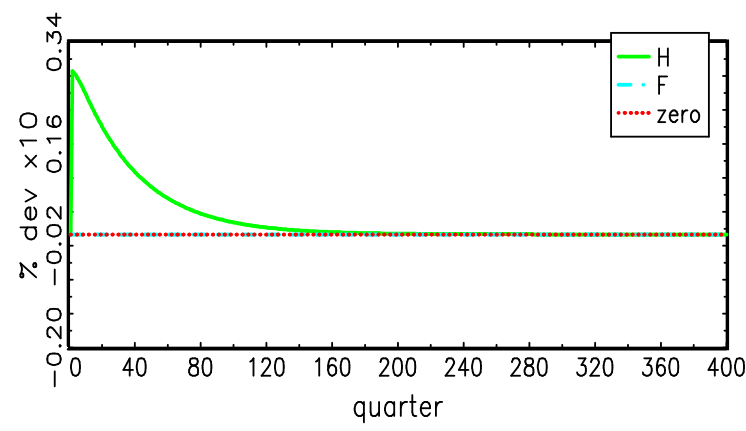

LI, T shock

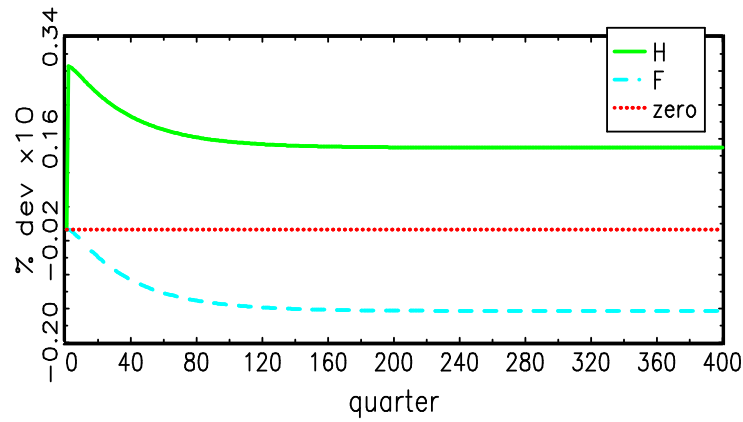

$H I$, T shock

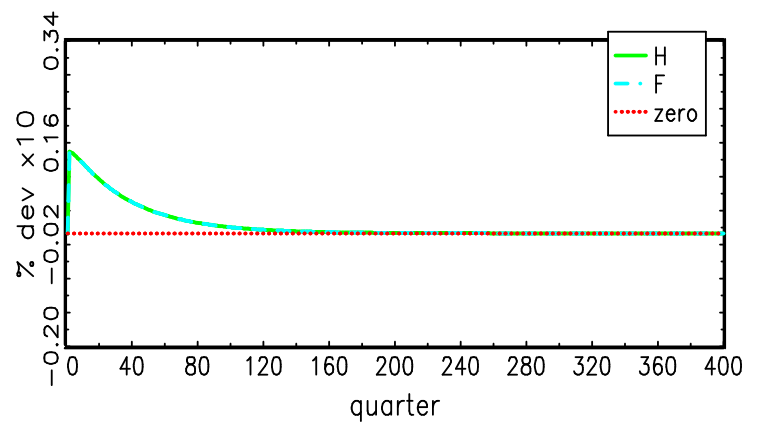

FA, N shock

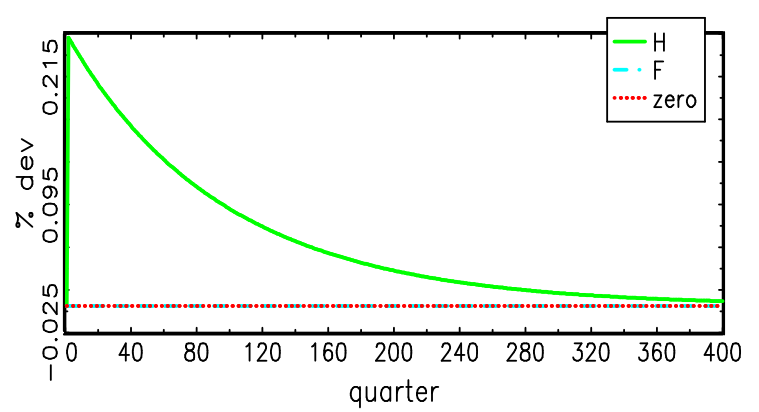

LI, N shock

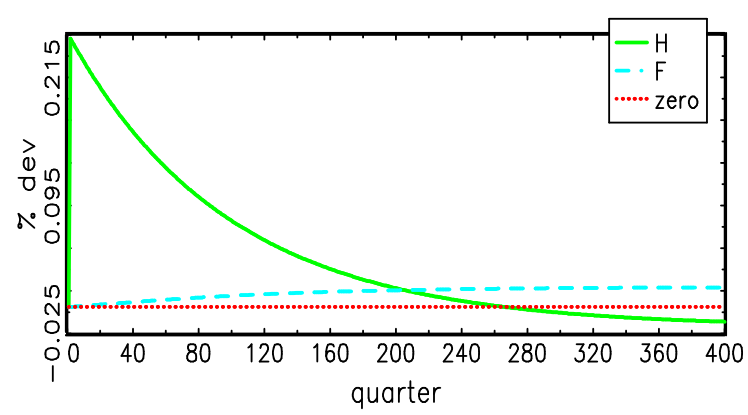

HI, N shock

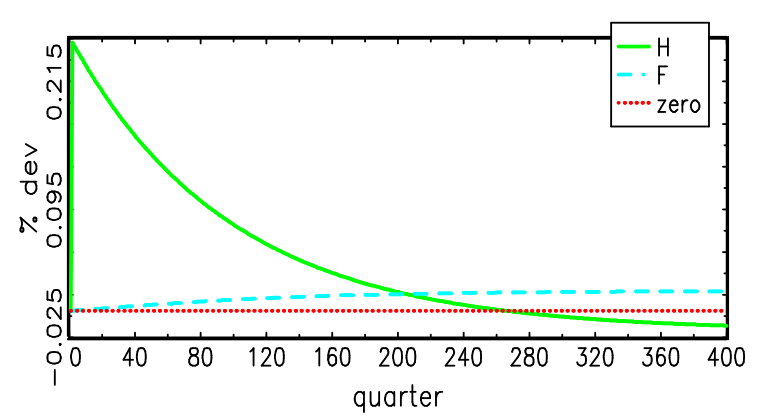

Figure 2: Impulse responses for the welfare of $\mathrm{H}$ and $\mathrm{F}$ households. The right and left hand columns show the effects of a positive one standard deviation shock to $\mathrm{H}$ productivity in the traded and nontraded sectors respectively. The upper, middel and lower panels correspond to the FA, LI and HI equilibira respectively. All responses are measured in $\%$ deviations of certainty equivalent consumption from the value implied by the initial international wealth distribution (i.e. the zero plot).

The welfare responses under $\mathrm{HI}$ are shown in the lower panel of Figure 2. The welfare implications of nontraded productivity shocks are exactly the same as under LI. This is not surprising. Under HI households are better able to hedge against the effects of foreign productivity shocks in the traded sector, but not in the nontraded sector. This means that the consumption implications of the nontraded productivity shocks are the same in the LI and HI equilibria, so we see the same welfare responses to the shocks. By the same 
token, the welfare implications of traded shocks differ between the LI and HI equilibria. In this case, portfolio diversification distributes the wealth effects of the shock equally between $\mathrm{H}$ and $\mathrm{F}$ households. As a result, the initial impact on welfare is universally positive but smaller than that experienced by $\mathrm{H}$ households in

the other equilibria. Furthermore, because the consumption implications of the traded shock are the same across countries, there is no long-run redistribution of wealth so the welfare effects are temporary.

Overall, the results depicted in Figure 2 show that the degree of financial integration has potentially significant implications for the welfare of individual households. In particular, the impulse responses show that households are more susceptible to permanent changes in welfare under LI than under either FA or HI. As consequence, it is perfectly possible for $\mathrm{H}$ households to find themselves with significantly lower or higher welfare by the end of a spell in the LI equilibrium, than would have been the case under HI or even FA. For example, $\mathrm{H}$ households are significantly worse off in the long run following a negative shock to H traded productivity under LI than under either HI or FA. In sum, the degree of financial integration has a significant impact on how the welfare implications of different productivity shocks are distributed through time and across households.

\section{Conclusions}

We have explored the role of international financial markets for dynamics of the real economy in a two-country two-sector general equilibrium model with production and dynamic portfolio choice. In this framework, we find that increased financial integration leads to higher output volatility, but its implications for consumption volatility are non-monotonic. Consistent with empirical evidence in Kose et.al. (2003), we find that volatility initially increases at the early stages of integration, and then declines as more instruments for international risk-sharing become available. We also examined the welfare implications of increased financial integration. Despite the significant gains in risk-sharing, we find that the unconditional welfare gains from greater integration are very small because there is no change in the world's long-run growth rate. Nevertheless, integration does affect the international distribution of welfare because it changes the long-run susceptibility of individual welfare to shocks.

While far from definitive, our findings suggest that in order to fully assess the welfare implications of financial integration we need to extend our model to incorporate endogenous long-run growth. Of course this takes us back to the seminal work of Obstfeld (1994). In this paper our focus has been on how households' access to foreign asset markets facilitates risk-sharing. Financial integration also allows firms to borrow or raise capital from a larger pool of households which in turn has the potential to lower the cost of capital. The question of how this affects the investment decisions of firms, long-run growth and welfare are left for the future. 


\section{References}

[1] Backus, David K., Kehoe, Patrick J., Kydland, Finn E. (1995). "International Business Cycles: Theory and Evidence". In: Cooley, T. (Ed.), Frontiers of Business Cycle Research. Princeton University Press, Princeton, 331-356.

[2] Baxter, Marianne, Urban J. Jermann, and Robert G. King (1998). "Nontraded Goods, Nontraded Factors and International Non-Diversification", Journal of International Economics 44, 211-229.

[3] Baxter, Marianne, and Mario J. Crucini (1995). "Business Cycles and the Asset Structure of Foreign Trade", International Economic Review 36, 821-854.

[4] Buch, Claudia M. and Christian Pierdzioch (2003). "The Integration of Imperfect Financial Markets: Implications for Business Cycle Volatility", Kiel Working Paper No. 1161.

[5] Campbell, John Y. and Robert J. Shiller (1989). "The Dividend-Price Ratio and Expectations of Future Dividends and Discount Factors", The Review of Financial Studies 1(3), 195-228.

[6] Cole, Harold L. and Maurice Obstfeld (1991). "Commodity Trade and International Risk Sharing: How Much Do Financial Markets Matter?", Journal of Monetary Economics 28, 3-24.

[7] Corsetti, Giancarlo, Luca Dedola and Sylvain Leduc (2003). "International Risk-Sharing and the Transmission of Productivity Shocks".

[8] Campbell, John Y., Yeung Lewis Chan, and Luis M. Viceira (2003). "A Multivariate Model of Strategic Asset Allocation", Journal of Financial Economics 67(1), 41-80.

[9] Devereux, Michael B. and Alan Sutherland (2006). "Solving for Country Portfolios in Open Economy Macro Models", Working Paper.

[10] Evans, Martin D. D. and Viktoria V. Hnatkovska (2005) "International Capital Flows, Returns and World Financial Integration", NBER working paper, No. 1170.

[11] _______(2006). "Solving General Equilibrium Models with Incomplete Markets and Many Assets" NBER technical working paper No. t0318.

[12] Ghironi, Fabio, Jaewoo Lee, and Alessandro Rebucci (2006). "The Valuation Channel of External Adjustment", Working Paper.

[13] Gourinchas, Pierre-Olivier and Olivier Jeanne (2006). "The Elusive Gains from International Financial Integration", Review of Economic Studies 73, 1-27.

[14] Heathcote, Jonathan and Fabrizio Perri (2002). "Financial Autarky and International Business Cycles", Journal of Monetary Economics 49, 601-627.

[15] Kim, Jinill, Sunghyun Henry Kim and Andrew Levin (2003). "Patience, Persistence, and Welfare Costs of Incomplete Markets in Open Economies", Journal of International Economics 61, 385-396. 
[16] Kose, M. Ayhan, Eswar S. Prasad, and Marco E. Terrones (2003). "Financial Integration and Macroeconomic Volatility", IMF Working Paper WP/03/50.

[17] Leblebicioglu, Asli (2005). "Financial Integration, Credit Market Imperfections and Consumption Smoothing", Boston College Working Paper.

[18] Obstfeld, Maurice (1994). "Risk-taking, Global Diversification, and Growth ", American Economic Review, 84, 1310-1329.

[19] Razin, Assaf and Andrew K. Rose (1994). "Business-Cycle Volatility and Openness: An Exploratory Cross-Sectional Analysis", in Leonardo Leiderman and Assaf Razin (eds.), "Capital Mobility: The Impact on Consumption, Investment, and Growth", Cambridge University Press, Cambridge, 48-76.

[20] Senay, Ozge (1998). "The Effects of Goods and Financial Market Integration on Macroeconomic Volatility", The Manchester School.

[21] Sutherland, Alan (1996). "Financial Market Integration and Macroeconomic Volatility", Scandinavian Journal of Economics 98 (4), 521-539.

[22] Tesar, Linda L. (1993). "International Risk Sharing and Non-Traded Goods", Journal of International Economics 35, 69-89.

[23] _______(1995). "Evaluating the Gains from International Risksharing", Carnegie-Rochester Conference Series on Public Policy 42, 95-143.

[24] Tille, Cedric and Eric van Wincoop (2006). "International Capital Flows", Working Paper.

[25] van Wincoop, Eric (1994). "Welfare Gains From International Risksharing", Journal of Monetary Economics $34,175-200$.

[26] van Wincoop, Eric (1999). "How Big are Potential Welfare Gains From International Risksharing?", Journal of International Economics 47, 109-135. 


\section{A Appendix:}

\section{A.1 Derivation of matrix $\mathbb{A}$}

We start by deriving the approximate process for quadratic and cross-product terms, $\tilde{x}_{t}$. In continuous time, the discrete process for $x_{t+1}$ in (27) can be written as

$$
d x_{t}=\left[\Phi_{0}-\Phi_{1} x_{t}+\Phi_{2} \tilde{x}_{t}\right] d t+\Omega\left(\tilde{x}_{t}\right)^{1 / 2} d W_{t}
$$

Then, by Ito's lemma, the process for $\tilde{x}_{t}$ is:

$$
\begin{aligned}
\operatorname{dvec}\left(x_{t} x_{t}^{\prime}\right)= & {\left[\left(I \otimes x_{t}\right)+\left(x_{t} \otimes I\right)\right]\left(\left[\Phi_{0}-\Phi_{1} x_{t}+\Phi_{2} \tilde{x}_{t}\right] d t+\Omega\left(\tilde{x}_{t}\right)^{1 / 2} d W_{t}\right) } \\
& +\frac{1}{2}\left[(I \otimes U)\left(\frac{\partial x}{\partial x^{\prime}} \otimes I\right)+\left(\frac{\partial x}{\partial x^{\prime}} \otimes I\right)\right] d[x, x]_{t} \\
= & {\left[\left(I \otimes x_{t}\right)+\left(x_{t} \otimes I\right)\right]\left(\left[\Phi_{0}-\Phi_{1} x_{t}+\Phi_{2} \tilde{x}_{t}\right] d t+\Omega\left(\tilde{x}_{t}\right)^{1 / 2} d W_{t}\right) } \\
& +\frac{1}{2}\left[\mathbb{U}\left(\frac{\partial x}{\partial x^{\prime}} \otimes I\right)+\left(\frac{\partial x}{\partial x^{\prime}} \otimes I\right)\right] \operatorname{vec}\left\{\Omega\left(\tilde{x}_{t}\right)\right\} d t \\
= & {\left[\left(I \otimes x_{t}\right)+\left(x_{t} \otimes I\right)\right]\left(\left[\Phi_{0}-\Phi_{1} x_{t}+\Phi_{2} \tilde{x}_{t}\right] d t+\Omega\left(\tilde{x}_{t}\right)^{1 / 2} d W_{t}\right)+\frac{1}{2} \operatorname{Dvec}\left\{\Omega\left(\tilde{x}_{t}\right)\right\} d t, }
\end{aligned}
$$

where

$$
D=\left[\mathbb{U}\left(\frac{\partial x}{\partial x^{\prime}} \otimes I\right)+\left(\frac{\partial x}{\partial x^{\prime}} \otimes I\right)\right], \quad \mathbb{U}=\sum_{r} \sum_{s} E_{r s} \otimes E_{r, s}^{\prime},
$$

and $E_{r, s}$ is the elementary matrix which has a unity at the $(r, s)^{t h}$ position and zero elsewhere. The law of motion for the quadratic states in (A1) can be rewritten in discrete time as

$$
\begin{aligned}
\tilde{x}_{t+1} \cong & \tilde{x}_{t}+\left[\left(I \otimes x_{t}\right)+\left(x_{t} \otimes I\right)\right]\left[\Phi_{0}-\Phi_{1} x_{t}+\Phi_{2} \tilde{x}_{t}\right]+\frac{1}{2} \operatorname{Dvec}\left(\Omega\left(\tilde{x}_{t}\right)\right) \\
& +\left[\left(I \otimes x_{t}\right)+\left(x_{t} \otimes I\right)\right] u_{t+1}, \\
\cong & \frac{1}{2} D \Sigma_{0}+\left[\left(\Phi_{0} \otimes I\right)+\left(I \otimes \Phi_{0}\right)\right] x_{t}+\left[I-\left(\Phi_{1} \otimes I\right)-\left(I \otimes \Phi_{1}\right)+\frac{1}{2} D \Sigma_{1}\right] \tilde{x}_{t}+\tilde{u}_{t+1},
\end{aligned}
$$

where $\tilde{u}_{t+1} \equiv\left[\left(I \otimes x_{t}\right)+\left(x_{t} \otimes I\right)\right] u_{t+1}$. The last equality is obtained by using an expression for vec $\left(\Omega\left(X_{t}\right)\right)$ in (??), where $\Sigma_{0}=\operatorname{vec}\left(\Omega_{0}\right)$ and $\Sigma_{1}=\Omega_{1} \otimes \Omega_{1}$, and by combining together the corresponding coefficients on a constant, linear and second-order terms.

We can now combine (27) and (A2) into a single equation:

$$
\left[\begin{array}{c}
1 \\
x_{t+1} \\
\tilde{x}_{t+1}
\end{array}\right]=\left[\begin{array}{ccc}
1 & 0 & 0 \\
\Phi_{0} & I-\Phi_{1} & \Phi_{2} \\
\frac{1}{2} D \Sigma_{0} & \left(\Phi_{0} \otimes I\right)+\left(I \otimes \Phi_{0}\right) & I-\left(\Phi_{1} \otimes I\right) \\
-\left(I \otimes \Phi_{1}\right)+\frac{1}{2} D \Sigma_{1}
\end{array}\right]\left[\begin{array}{c}
1 \\
x_{t} \\
\tilde{x}_{t}
\end{array}\right]+\left[\begin{array}{c}
0 \\
u_{t+1} \\
\tilde{u}_{t+1}
\end{array}\right],
$$

or more compactly

$$
X_{t+1}=\mathbb{A} X_{t}+U_{t+1},
$$




\section{A.2 Derivation of matrix $\mathbb{S}$}

Recall that $U_{t+1}=\left[\begin{array}{lll}0 & u_{t+1} & \tilde{u}_{t+1}\end{array}\right]^{\prime}$, with $\mathbb{E}\left(u_{t+1} u_{t+1}^{\prime} \mid x_{t}\right)=\Omega\left(X_{t}\right)=\Omega_{0}+\Omega_{1} x_{t} x_{t}^{\prime} \Omega_{1}^{\prime}$. This implies $\mathbb{E}\left(U_{t+1} \mid X_{t}\right)=0$ and

$$
\mathbb{E}\left(U_{t+1} U_{t+1}^{\prime} \mid X_{t}\right) \equiv \mathbb{S}\left(X_{t}\right)=\left(\begin{array}{ccc}
0 & 0 & 0 \\
0 & \Omega\left(X_{t}\right) & \Gamma\left(X_{t}\right) \\
0 & \Gamma\left(X_{t}\right)^{\prime} & \Psi\left(X_{t}\right)
\end{array}\right)
$$

To evaluate the covariance matrix, we assume that $\operatorname{vec}\left(x_{t+1} \tilde{x}_{t+1}^{\prime}\right) \cong 0$ and define:

$$
\begin{aligned}
\Gamma\left(X_{t}\right) \equiv & \mathbb{E}_{t} u_{t+1} \tilde{u}_{t+1}^{\prime} \\
= & \mathbb{E}_{t} x_{t+1} \tilde{x}_{t+1}^{\prime}-\mathbb{E}_{t} x_{t+1} \mathbb{E}_{t} \tilde{x}_{t+1}^{\prime} \\
= & \mathbb{E}_{t} x_{t+1} \tilde{x}_{t+1}^{\prime}-\left(\Phi_{0}+\left(I-\Phi_{1}\right) x_{t}+\Phi_{2} \tilde{x}_{t}\right) \\
& \times\left(\frac{1}{2} \Sigma_{0}^{\prime} D^{\prime}+x_{t}^{\prime}\left[\left(\Phi_{0} \otimes I\right)+\left(I \otimes \Phi_{0}\right)\right]^{\prime}+\tilde{x}_{t}^{\prime}\left[I-\left(\left(\Phi_{1} \otimes I\right)+\left(I \otimes \Phi_{1}\right)\right)+\frac{1}{2} D \Sigma_{1}\right]^{\prime}\right) \\
\cong & -\Phi_{0}\left(\frac{1}{2} \Sigma_{0}^{\prime} D^{\prime}+x_{t}^{\prime}\left[\left(\Phi_{0} \otimes I\right)+\left(I \otimes \Phi_{0}\right)\right]^{\prime}+\tilde{x}_{t}^{\prime}\left[I-\left(\left(\Phi_{1} \otimes I\right)+\left(I \otimes \Phi_{1}\right)\right)+\frac{1}{2} D \Sigma_{1}\right]^{\prime}\right) \\
& -\left(I-\Phi_{1}\right) x_{t}\left(\frac{1}{2} \Sigma_{0}^{\prime} D^{\prime}+x_{t}^{\prime}\left[\left(\Phi_{0} \otimes I\right)+\left(I \otimes \Phi_{0}\right)\right]^{\prime}\right)-\frac{1}{2} \Phi_{2} \tilde{x}_{t} \Sigma_{0}^{\prime} D^{\prime} \\
= & -\frac{1}{2} \Phi_{0} \Sigma_{0}^{\prime} D^{\prime}-\Phi_{0} x_{t}^{\prime}\left[\left(\Phi_{0} \otimes I\right)+\left(I \otimes \Phi_{0}\right)\right]^{\prime}-\frac{1}{2}\left(I-\Phi_{1}\right) x_{t} \Sigma_{0}^{\prime} D^{\prime} \\
& -\Phi_{0} \tilde{x}_{t}^{\prime}\left[I-\left(\left(\Phi_{1} \otimes I\right)+\left(I \otimes \Phi_{1}\right)\right)+\frac{1}{2} D \Sigma_{1}\right]^{\prime}-\left(I-\Phi_{1}\right) x_{t} x_{t}^{\prime}\left[\left(\Phi_{0} \otimes I\right)+\left(I \otimes \Phi_{0}\right)\right]^{\prime}-\frac{1}{2} \Phi_{2} \tilde{x}_{t} \Sigma_{0}^{\prime} D^{\prime} .
\end{aligned}
$$

Hence

$$
\begin{aligned}
\operatorname{vec}\left(\Gamma\left(X_{t}\right)\right)= & \Gamma_{0}+\Gamma_{1} x_{t}+\Gamma_{2} \tilde{x}_{t}, \\
\Gamma_{0}= & -\frac{1}{2}\left(D \Sigma_{0} \otimes \Phi_{0}\right) \operatorname{vec}(I), \\
\Gamma_{1}= & -\left[\left(\Phi_{0} \otimes I\right)+\left(I \otimes \Phi_{0}\right)\right] \otimes \Phi_{0}+\frac{1}{2}\left(D \Sigma_{0} \otimes\left(I-\Phi_{1}\right)\right), \\
\Gamma_{2}= & -\left[I-\left(\left(\Phi_{1} \otimes I\right)+\left(I \otimes \Phi_{1}\right)\right)+\frac{1}{2} D \Sigma_{1}\right] \otimes \Phi_{0}-\frac{1}{2}\left(D \Sigma_{0} \otimes \Phi_{2}\right) \\
& -\left[\left(\Phi_{0} \otimes I\right)+\left(I \otimes \Phi_{0}\right)\right] \otimes\left(I-\Phi_{1}\right) .
\end{aligned}
$$

Note also from above that

$$
\begin{aligned}
\Gamma\left(X_{t}\right)^{\prime}= & -\frac{1}{2} D \Sigma_{0} \Phi_{0}^{\prime}-\left[\left(\Phi_{0} \otimes I\right)+\left(I \otimes \Phi_{0}\right)\right] x_{t} \Phi_{0}^{\prime}-\Sigma_{0} x_{t}^{\prime}\left(I-\Phi_{1}\right)^{\prime} \\
& -\left[I-\left(\left(\Phi_{1} \otimes I\right)+\left(I \otimes \Phi_{1}\right)\right)+\frac{1}{2} D \Sigma_{1}\right] \tilde{x}_{t} \Phi_{0}^{\prime}-\left[\left(\Phi_{0} \otimes I\right)+\left(I \otimes \Phi_{0}\right)\right] x_{t} x_{t}^{\prime}\left(I-\Phi_{1}\right)^{\prime}-\frac{1}{2} D \Sigma_{0} \tilde{x}_{t}^{\prime} \Phi_{2}^{\prime} .
\end{aligned}
$$

So

$$
\begin{aligned}
\operatorname{vec}\left(\Gamma\left(X_{t}\right)^{\prime}\right)= & \Lambda_{0}+\Lambda_{1} x_{t}+\Lambda_{2} \tilde{x}_{t}, \\
\Lambda_{0}= & -\frac{1}{2}\left(\Phi_{0} \otimes D \Sigma_{0}\right) \operatorname{vec}(I), \\
\Lambda_{1}= & -\left(\Phi_{0} \otimes\left[\left(\Phi_{0} \otimes I\right)+\left(I \otimes \Phi_{0}\right)\right]\right)+\frac{1}{2}\left(\left(I-\Phi_{1}\right) \otimes D \Sigma_{0}\right), \\
\Lambda_{2}= & -\left(\Phi_{0} \otimes\left[I-\left(\left(\Phi_{1} \otimes I\right)+\left(I \otimes \Phi_{1}\right)\right)+\frac{1}{2} D \Sigma_{1}\right]\right)-\frac{1}{2}\left(\Phi_{2} \otimes D \Sigma_{0}\right) \\
& -\left(\left(I-\Phi_{1}\right) \otimes\left[\left(\Phi_{0} \otimes I\right)+\left(I \otimes \Phi_{0}\right)\right]\right) .
\end{aligned}
$$


Next, consider the variance of $\tilde{u}_{t+1}$ :

$$
\begin{aligned}
\Psi\left(X_{t}\right) \equiv & \mathbb{E}_{t} \tilde{u}_{t+1} \tilde{u}_{t+1}^{\prime}=\mathbb{E}_{t} \tilde{x}_{t+1} \tilde{x}_{t+1}^{\prime}-\mathbb{E}_{t} \tilde{x}_{t+1} \mathbb{E}_{t} \tilde{x}_{t+1}^{\prime} \\
= & \mathbb{E}_{t} \tilde{x}_{t+1} \tilde{x}_{t+1}^{\prime}-\left(\frac{1}{2} D \Sigma_{0}+\left[\left(\Phi_{0} \otimes I\right)+\left(I \otimes \Phi_{0}\right)\right] x_{t}+\left[I-\left(\left(\Phi_{1} \otimes I\right)+\left(I \otimes \Phi_{1}\right)\right)+\frac{1}{2} D \Sigma_{1}\right] \tilde{x}_{t}\right) \\
& \times\left(\frac{1}{2} \Sigma_{0}^{\prime} D^{\prime}+x_{t}^{\prime}\left[\left(\Phi_{0} \otimes I\right)+\left(I \otimes \Phi_{0}\right)\right]^{\prime}+\tilde{x}_{t}^{\prime}\left[I-\left(\left(\Phi_{1} \otimes I\right)+\left(I \otimes \Phi_{1}\right)\right)+\frac{1}{2} D \Sigma_{1}\right]^{\prime}\right) \\
\cong & -\frac{1}{2} D \Sigma_{0}\left(\frac{1}{2} \Sigma_{0}^{\prime} D^{\prime}+x_{t}^{\prime}\left[\left(\Phi_{0} \otimes I\right)+\left(I \otimes \Phi_{0}\right)\right]^{\prime}+\tilde{x}_{t}^{\prime}\left[I-\left(\left(\Phi_{1} \otimes I\right)+\left(I \otimes \Phi_{1}\right)\right)+\frac{1}{2} D \Sigma_{1}\right]^{\prime}\right) \\
& -\left[\left(\Phi_{0} \otimes I\right)+\left(I \otimes \Phi_{0}\right)\right] x_{t}\left(\frac{1}{2} \Sigma_{0}^{\prime} D^{\prime}+x_{t}^{\prime}\left[\left(\Phi_{0} \otimes I\right)+\left(I \otimes \Phi_{0}\right)\right]^{\prime}\right) \\
& -\left[I-\left(\left(\Phi_{1} \otimes I\right)+\left(I \otimes \Phi_{1}\right)\right)+\frac{1}{2} \mathbb{D} \Sigma_{1}\right] \tilde{x}_{t} \frac{1}{2} \Sigma_{0}^{\prime} D^{\prime}, \\
= & -\frac{1}{4} D \Sigma_{0} \Sigma_{0}^{\prime} D^{\prime}-\frac{1}{2} D \Sigma_{0} x_{t}^{\prime}\left[\left(\Phi_{0} \otimes I\right)+\left(I \otimes \Phi_{0}\right)\right]^{\prime}-\frac{1}{2}\left[\left(\Phi_{0} \otimes I\right)+\left(I \otimes \Phi_{0}\right)\right] x_{t} \Sigma_{0}^{\prime} D^{\prime} \\
& -\frac{1}{2} D \Sigma_{0} \tilde{x}_{t}^{\prime}\left[I-\left(\left(\Phi_{1} \otimes I\right)+\left(I \otimes \Phi_{1}\right)\right)+\frac{1}{2} D \Sigma_{1}\right]^{\prime}-\left[\left(\Phi_{0} \otimes I\right)+\left(I \otimes \Phi_{0}\right)\right] x_{t} x_{t}^{\prime}\left[\left(\Phi_{0} \otimes I\right)+\left(I \otimes \Phi_{0}\right)\right]^{\prime} \\
& -\frac{1}{2}\left[I-\left(\left(\Phi_{1} \otimes I\right)+\left(I \otimes \Phi_{1}\right)\right)+\frac{1}{2} D \Sigma_{1}\right] \tilde{x}_{t} \Sigma_{0}^{\prime} D^{\prime} .
\end{aligned}
$$

Hence,

$$
\begin{aligned}
\operatorname{vec}\left(\Psi\left(X_{t}\right)\right)= & \Psi_{0}+\Psi_{1} x_{t}+\Psi_{2} \tilde{x}_{t} \\
\Psi_{0}= & -\frac{1}{4}\left(D \Sigma_{0} \otimes D \Sigma_{0}\right) \operatorname{vec}(I) \\
\Psi_{1}= & -\frac{1}{2}\left(\left[\left(\Phi_{0} \otimes I\right)+\left(I \otimes \Phi_{0}\right)\right] \otimes D \Sigma_{0}\right)-\frac{1}{2}\left(D \Sigma_{0} \otimes\left[\left(\Phi_{0} \otimes I\right)+\left(I \otimes \Phi_{0}\right)\right]\right) \\
\Psi_{2}= & -\frac{1}{2}\left[I-\left(\left(\Phi_{1} \otimes I\right)+\left(I \otimes \Phi_{1}\right)\right)+\frac{1}{2} D \Sigma_{1}\right] \otimes D \Sigma_{0}-\frac{1}{2}\left(D \Sigma_{0} \otimes\left[I-\left(\left(\Phi_{1} \otimes I\right)+\left(I \otimes \Phi_{1}\right)\right)+\frac{1}{2} D \Sigma_{1}\right]\right) \\
& -\left[\left(\Phi_{0} \otimes I\right)+\left(I \otimes \Phi_{0}\right)\right] \otimes\left[\left(\Phi_{0} \otimes I\right)+\left(I \otimes \Phi_{0}\right)\right] .
\end{aligned}
$$

\section{A.3 Derivation of $\mathcal{A}(.,$.$) and \mathcal{B}(.,$.}

Let $a_{t}=\pi_{a} X_{t}$ and $b_{t}=\pi_{b} X_{t}$ for two variables $a_{t}$ and $b_{t}$. We want to find the conditional covariance between $a_{t+1}$ and $b_{t+1}$ as defined in equation (30):

$$
\begin{aligned}
\mathbb{C V}_{t}\left(a_{t+1}, b_{t+1}\right)= & {\left[\begin{array}{lll}
\pi_{a}^{0} & \pi_{a}^{1} & \pi_{a}^{2}
\end{array}\right]\left[\begin{array}{ccc}
0 & 0 & 0 \\
0 & \Omega\left(X_{t}\right) & \Gamma\left(X_{t}\right) \\
0 & \Gamma\left(X_{t}\right)^{\prime} & \Psi\left(X_{t}\right)
\end{array}\right]\left[\begin{array}{c}
\pi_{b}^{0 \prime} \\
\pi_{b}^{1 \prime} \\
\pi_{b}^{2 \prime}
\end{array}\right], } \\
= & \pi_{a}^{1} \Omega\left(X_{t}\right) \pi_{b}^{1 \prime}+\pi_{a}^{2} \Gamma\left(X_{t}\right)^{\prime} \pi_{b}^{1 \prime}+\pi_{a}^{1} \Gamma\left(X_{t}\right) \pi_{b}^{2 \prime}+\pi_{a}^{2} \Psi\left(X_{t}\right) \pi_{b}^{2 \prime}, \\
= & \left(\pi_{b}^{1} \otimes \pi_{a}^{1}\right) \operatorname{vec}\left(\Omega\left(X_{t}\right)\right)+\left(\pi_{b}^{1} \otimes \pi_{a}^{2}\right) \operatorname{vec}\left(\Gamma\left(X_{t}\right)^{\prime}\right) \\
& +\left(\pi_{b}^{2} \otimes \pi_{a}^{1}\right) \operatorname{vec}\left(\Gamma\left(X_{t}\right)\right)+\left(\pi_{b}^{2} \otimes \pi_{a}^{2}\right) \operatorname{vec}\left(\Psi\left(X_{t}\right)\right), \\
= & \left(\pi_{b}^{1} \otimes \pi_{a}^{1}\right) \Sigma_{0}+\left(\pi_{b}^{1} \otimes \pi_{a}^{2}\right) \Lambda_{0}+\left(\pi_{b}^{2} \otimes \pi_{a}^{1}\right) \Gamma_{0}+\left(\pi_{b}^{2} \otimes \pi_{a}^{2}\right) \Psi_{0} \\
& +\left(\left(\pi_{b}^{1} \otimes \pi_{a}^{2}\right) \Lambda_{1}+\left(\pi_{b}^{2} \otimes \pi_{a}^{1}\right) \Gamma_{1}+\left(\pi_{b}^{2} \otimes \pi_{a}^{2}\right) \Psi_{1}\right) x_{t} \\
& +\left(\left(\pi_{b}^{1} \otimes \pi_{a}^{1}\right) \Sigma_{1}+\left(\pi_{b}^{1} \otimes \pi_{a}^{2}\right) \Lambda_{2}+\left(\pi_{b}^{2} \otimes \pi_{a}^{1}\right) \Gamma_{2}+\left(\pi_{b}^{2} \otimes \pi_{a}^{2}\right) \Psi_{2}\right) \tilde{x}_{t} .
\end{aligned}
$$


So, to summarize,

$$
\begin{aligned}
\mathbb{C V}_{t}\left(a_{t+1}, b_{t+1}\right) & =\mathcal{A}\left(\pi_{a}, \pi_{b}\right) X_{t}, \\
\mathcal{A}\left(\pi_{a}, \pi_{b}\right) & =\left[\begin{array}{lll}
\mathcal{A}_{a, b}^{0} & \mathcal{A}_{a, b}^{1} & \mathcal{A}_{a, b}^{2}
\end{array}\right], \\
\mathcal{A}_{a, b}^{0} & =\left(\pi_{b}^{1} \otimes \pi_{a}^{1}\right) \Sigma_{0}+\left(\pi_{b}^{1} \otimes \pi_{a}^{2}\right) \Lambda_{0}+\left(\pi_{b}^{2} \otimes \pi_{a}^{1}\right) \Gamma_{0}+\left(\pi_{b}^{2} \otimes \pi_{a}^{2}\right) \Psi_{0}, \\
\mathcal{A}_{a, b}^{1} & =\left(\pi_{b}^{1} \otimes \pi_{a}^{2}\right) \Lambda_{1}+\left(\pi_{b}^{2} \otimes \pi_{a}^{1}\right) \Gamma_{1}+\left(\pi_{b}^{2} \otimes \pi_{a}^{2}\right) \Psi_{1}, \\
\mathcal{A}_{a, b}^{2} & =\left(\pi_{b}^{1} \otimes \pi_{a}^{1}\right) \Sigma_{1}+\left(\pi_{b}^{1} \otimes \pi_{a}^{2}\right) \Lambda_{2}+\left(\pi_{b}^{2} \otimes \pi_{a}^{1}\right) \Gamma_{2}+\left(\pi_{b}^{2} \otimes \pi_{a}^{2}\right) \Psi_{2} .
\end{aligned}
$$

To obtain the products of two vectors $a_{t}$ and $b_{t}$ as defined in (31), we note that

$$
\begin{aligned}
a_{t} b_{t}= & \pi_{a} X_{t} X_{t}^{\prime} \pi_{b}^{\prime} \\
= & {\left[\begin{array}{lll}
\pi_{a}^{0} & \pi_{a}^{1} & \pi_{a}^{2}
\end{array}\right]\left[\begin{array}{ccc}
1 & x_{t}^{\prime} & \tilde{x}_{t}^{\prime} \\
x_{t} & x_{t} x_{t}^{\prime} & 0 \\
\tilde{x}_{t} & 0 & 0
\end{array}\right]\left[\begin{array}{c}
\pi_{b}^{0 \prime} \\
\pi_{b}^{1 \prime} \\
\pi_{b}^{2 \prime}
\end{array}\right], } \\
= & \left(\pi_{a}^{0}+\pi_{a}^{1} x_{t}+\pi_{a}^{2} \tilde{x}_{t}\right) \pi_{b}^{0 \prime}+\left(\pi_{a}^{0} x_{t}^{\prime}+\pi_{a}^{1} x_{t} x_{t}^{\prime}\right) \pi_{b}^{1 \prime}+\pi_{a}^{0} \tilde{x}_{t}^{\prime} \pi_{b}^{2 \prime}, \\
= & \left(\pi_{b}^{0} \otimes \pi_{a}^{0}\right)+\left(\pi_{b}^{0} \otimes \pi_{a}^{1}\right) x_{t}+\left(\pi_{b}^{0} \otimes \pi_{a}^{2}\right) \tilde{x}_{t}+\left(\pi_{b}^{1} \otimes \pi_{a}^{0}\right) x_{t} \\
& +\left(\pi_{b}^{1} \otimes \pi_{a}^{1}\right) \tilde{x}_{t}+\left(\pi_{b}^{2} \otimes \pi_{a}^{0}\right) \tilde{x}_{t} .
\end{aligned}
$$

Hence

$$
\begin{aligned}
& \pi_{a} X_{t} X_{t}^{\prime} \pi_{b}^{\prime}=\mathcal{B}\left(\pi_{a}, \pi_{b}\right) X_{t}, \\
& \mathcal{B}\left(\pi_{a}, \pi_{b}\right)=\left[\begin{array}{lll}
\mathcal{B}_{a, b}^{0} & \mathcal{B}_{a, b}^{1} & \mathcal{B}_{a, b}^{2}
\end{array}\right], \\
& \mathcal{B}_{a, b}^{0}=\left(\pi_{b}^{0} \otimes \pi_{a}^{0}\right) \operatorname{vec}(I)=\operatorname{vec}\left(\pi_{b}^{0} * \pi_{a}^{0}\right), \\
& \mathcal{B}_{a, b}^{1}=\left(\pi_{b}^{0} \otimes \pi_{a}^{1}\right)+\left(\pi_{b}^{1} \otimes \pi_{a}^{0}\right), \\
& \mathcal{B}_{a, b}^{2}=\left(\pi_{b}^{0} \otimes \pi_{a}^{2}\right)+\left(\pi_{b}^{1} \otimes \pi_{a}^{1}\right)+\left(\pi_{b}^{2} \otimes \pi_{a}^{0}\right) .
\end{aligned}
$$

